\title{
LA. SUB-. 94.29
}

\section{SPECIAL OPERATIO
(SOF)}

\section{TECHNICAL ANALYSIS \\ AND EVALUATION}

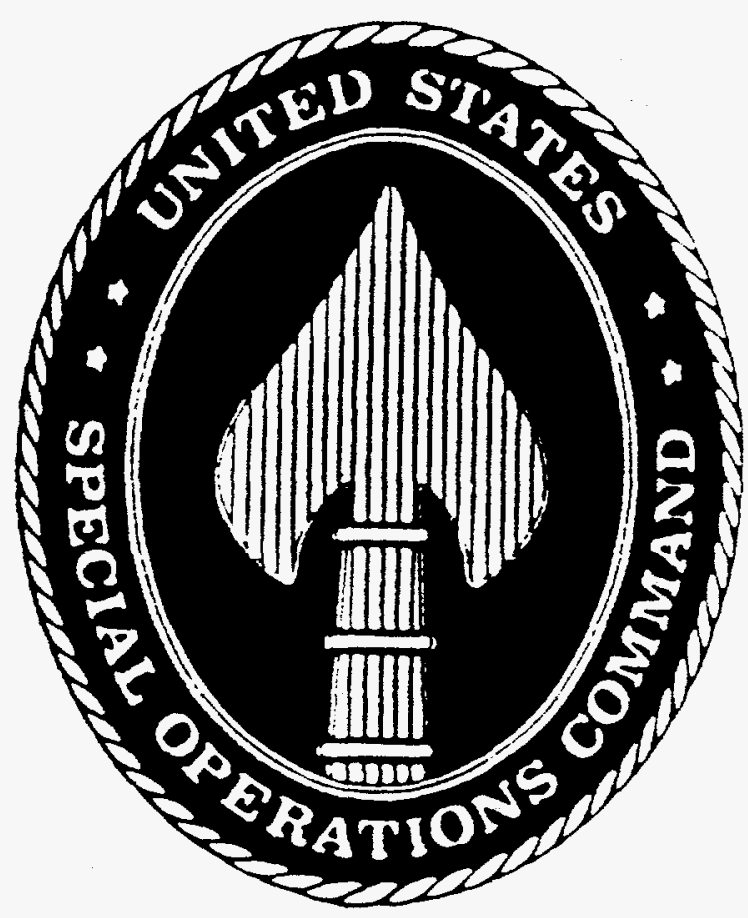

AUGUST 31, 1987

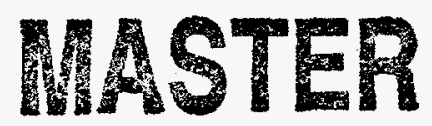

$$
\begin{aligned}
& q-\angle 5+1-1508 p-1 \\
& \text { DrotgRuTH } \\
& \text { PREPARED BY: }
\end{aligned}
$$




\section{DISCLAIMER}

Portions of this document may be illegible in electronic image products. Images are produced from the best available original document. 


\title{
FOREWORD
}

The attached papers represent quick response analytical efforts to assist USSOCOM in short-, medium- and long-range planning efforts. These papers do not, nor were they intended to, solve all the issues presented. Our intent is to (1) identify and present fundamental issues, (2) point the way to potential solutions, and (3) suggest possible courses of action for USSOCOM consideration.

This thirty-day effort was designed to provide overview discussions in various critical areas and expedite the results to the USSOCOM staff for planning purposes. We fully realize that the USSOCOM staff is working many of these issues in parallel to Betac and, in many instances, are actively seeking solutions to the issues and problems discussed herein. Although we make statements that may be considered obvious, it is not our intent to indicate that the USSOCOM staff is not aware or informed; we know they are.

\section{DISCLAIMER}

\begin{abstract}
This report was prepared as an account of work sponsored by an agency of the United States Government. Neither the United States Government nor any agency thereof, nor any of their employees, makes any warranty, express or implied, or assumes any legal liability or responsibility for the accuracy, completeness, or usefulness of any information, apparatus, product, or process disclosed, or represents that its use would not infringe privately owned rights. Reference herein to any specific commercial product, process, or service by trade name, trademark, manufacturer, or otherwise does not necessarily constitute or imply its endorsement, recommendation, or favoring by the United States Government or any agency thereof. The views and opinions of authors expressed herein do not necessarily state or reflect those of the United States Government or any agency thereof.
\end{abstract}




\section{EXECUTIVE SUMMARY}

In response to Task Order 001, Los Alamos National Laboratory Contract 9-L5H-1508P-1, Betac Corporation is pleased to provide ten quick-response, short-term analytical papers in support of Low Intensity Conflict (LIC) and Special Operations (SO). The papers are study methodologies which provide background, baseline, concepts, approaches, and recommendations in the mission areas identified in the Statement of Work. Although the Statement of Work specifies only nine papers, we have included a tenth paper addressing Command Relationships, since this subject affects all other topics and is of critical importance to USCINCSOC in establishing the United States Special Operations Command (USSOCOM). Each paper addresses the feasibility of further effort in each area of interest. The ten papers address:

- Mission Support Systems

- Research, Development, and Acquisition

- Headquarters Equipment

- C3I Architecture

- Intelligence Dissemination

- Intelligence Collection Management

- Intelligence Support to SOF Targeting

- Joint Mission Area Analysis (JMAA)

- Joint SOF Master Plan

- Command Relationships 
Throughout our analysis, a number of common themes appear:

- USSOCOM lacks SOF-experienced personnel to work the issues and problems associated with the unique and joint nature of SOF and the USSOCOM.

- There is uncertainty concerning Major Force Program (MFP) 11 and USSOCOM roles and responsibilities in the PPBS process.

- Baseline data does not exist.

- USCINCSOC's role as either a supported or a supporting CINC presents unique challenges.

- USSOCOM's role in low intensity conflict requires clarification.

- Existing C3I and other systems must be exercised to determine capabilities and identify shortfalls.

The lack of SOF-experienced personnel assigned to USSOCOM is a tremendous short-term problem facing USSOCOM. USCINCSOC must accelerate assignment of SOF experience into his command. He has a genuine need for immediate assistance from the Services and the other unified CINCs and should ask for SOF-experienced personnel to be assigned to USSOCOM on a temporary duty basis from other commands.

The uncertainty associated with management and control of MFP 11 funds casts a cloud over virtually every USSOCOM mission area. For the time being, USSOCOM must accept existing Service control of funds and programs; however, the command must work to build its own capability to monitor and to control MFP-11 aspects of the Planning, Programming, and Budgeting System (PPBS). The current arrangement requires either a waiver or a change to the law. 
Baseline data is lacking in every area. USSOCOM may be able to apply experience from other commands, such as USCENTCOM and the component Joint Special Operations Command (JSOC). USSOCOM's relationship to the theater command Special Operations Components (SOCs) will provide other vital areas of discovery and cooperation.

The role of USSOCOM in low intensity conflict and the command's relationship to the Assistant Secretary of Defense for Special Operations and Low Intensity Conflict, $\mathrm{ASD}$ (SO/LIC), is still unclear. Although solutions will develop along with both staffs, further defining this mission area will help in developing a more complete understanding of USCINCSOC's role as both a supporting and a supported CINC.

In these and other critical areas, many issues must be clarified and resolved. In the interim, the USSOCOM staff must learn a new mission, identify obstacles which can be overcome, and prioritize the needs of USCINCSOC. The first task is to develop an agenda and a timetable. The recommendations in this study effort should assist the command in this crucial task.

The following paragraphs summarize the contents and recommendations of the ten papers.

Mission Support Systems. This paper assesses requirements for logistic support: storage, contracting, maintenance, distribution and other support systems needed to maintain SOF readiness. We recommend that USSOCOM perform an inventory of SOF supplies on hand, SOF support programmed, and management activities in each component Service. The goal is to identify: (1) items that are SOF-specific and which USSOCOM should manage (explosives, radios, night optical devices, etc.); (2) items that 
are Service-common and can best be managed by the Services (most aircraft parts, uniform items, rations, etc.); and (3) those special supplies to support LIC (PROJECT STOCKS). USSOCOM should investigate the need for increased force activity designator (FAD) priority. The command should review storage requirements in theater war plans to ensure appropriate SOF support to the War Mobility Plan (WMP). As is the case with most of the areas studied, USSOCOM should solicit help and advice from outside agencies and take advantage of existing Service logistics systems.

Research, Development, and Acquisition (RD\&A): The RD\&A paper focuses on control of MFP 11. USSOCOM must clearly define its role and participation in Service RD\&A programs. This ties directly to the PPBS process and requires the command to develop expertise in program management and monitoring. USSOCOM should solicit assistance from the Service RD\&A commands, OSD, and outside agencies such as the Defense Advanced Research Projects Agency (DARPA) and the National Laboratories. USSOCOM must have a cleared cadre working with compartmented (black) programs to monitor emerging technology applicable to SOF. USCINCSOC must assume an aggressive role in the Defense Resources Board (DRB) process. The command's ability to develop a quick response capability (QRC) will be directly related to its role in the RD\&A process.

Headquarters Equipment: USCINCSOC should form a "Tiger Team" of experienced SOF personnel to conduct an exhaustive review of the types of information and connectivity at the Headquarters. The entire staff must be examined to determine a baseline of operational, logistical, intelligence planning, and command information requirements. The team should begin immediately and report to USCINCSOC monthly until the command is fully operational. The command should take full advantage of 
current contract efforts in the C3I area, but the team must also address the questions of basic telephone and office computer networks. This effort must consider the need for a mobile capability supporting emergency relocation and personal support to the CINC. Significantly, MacDill AFB C3 systems are already saturated with USCENTCOM activity.

Command, Control, Communications, and Intelligence (C3I) Architecture: C3I issues cross a number of functional lines in USSOCOM and extend outward to encompass the entire network of commands and agencies involved in SOF/LIC matters. Baseline and programmed upgrades must be inventoried. Two on-going contracts are looking at C3 and intelligence architecture requirements. These efforts should be exploited in developing a final C3I architecture to serve USSOCOM needs. We recommend that JSAG analyze the need for a standing SOF Joint Task Force (JTF). We strongly suggest that JSOC not assume this role because its primary mission would be diluted.

Intelligence Dissemination: This paper analyzes the dissemination process and discusses equipment and limitations. An important first step is to define total intelligence support requirements prior to focusing on dissemination needs. We recommend baselining capabilities, comparing requirements with existing capabilities and programmed upgrades, pursuing emerging technology, exploiting on-going contract efforts, and establishing a requirements validation procedure to address shortfalls through the PPBS. We outline specific actions to define total intelligence support requirements. 
Intelligence Support to Special Operations Forces Targeting: Special characteristics of SOF targeting stem from the need to covertly infiltrate, exfiltrate, and operate in hostile territory. This paper addresses key components of the SOF targeting process: target identification, target accessability, target criticality, weaponeering, target vulnerability, and recoverability. SOF targeting requires special skills in time- critical mission planning, timely all-source intelligence, and low probability intercept/detection (LPI/LPD) communications. USSOCOM will be able to provide significant assistance to theater commands in target folder production and updating. This will complement, rather than compete with, the efforts of the Theater Special Operations Components (SOCs).

Intelligence Collection Management for USSOCOM: SOF intelligence needs are very small compared to overall intelligence requirements. Collection priorities are not high enough on a day-to-day basis to consistently exercise the intelligence channels and methods needed to support LIC or SOF operations. Intelligence needs vary considerably among the command's missions as well. For example, there is considerable difference between LIC requirements and intelligence support to contingency operations. We recommend: identifying specific organizations, offices, individuals, communication links, and collection managers with direct involvement in SOF intelligence support; developing a cadre of SOF-experienced USSOCOM personnel who also understand the intelligence collection process; establishing and exercising close working relationships with the collection managers at all levels. Baseline information on current capabilities and programmed improvements in collection capability is again essential. 
Joint Mission Area Analysis (JMAA): This paper reviews the legislation and JCS charter establishing the command and focuses on its missions and functions. It is essential that USSOCOM review its mission areas--counterterrorism, unconventional warfare, and low intensity conflict--for baseline capabilities and shortfalls. The review should parallel the pending October 1987 report by the President to Congress addressing threats, capabilities, deficiencies, and required improvements to U.S. capabilities in special operations and low intensity conflict. USSOCOM should work closely with the Services and other unified commands to develop expertise in identifying threats, evaluating capabilities, and determining requirements. This must be done from a joint SOF perspective. The command must apply this same process to support and other functions such as training, retention, promotions, and readiness. Effective JMAA establishes the basis of the USSOCOM Joint SOF Master Plan.

Joint Special Operations Forces Master Plan: USSOCOM must review recent Service efforts to publish SOF master plans. The master plan must address three broad categories: a command baseline, a review of programmed improvements, and a well reasoned roadmap to achieve future goals and redress shortfalls. The plan must have a joint, rather than a Service, perspective, with special annexes to cover key mission areas. There is a real need for balanced force growth to allow USSOCOM to employ its resources effectively in joint operations.

Command Relationships: USSOCOM command relationships are both internal and external. Internal relationships involve assigned forces and command involvement with components and their parent Services. External relationships focus on SOF readiness to support other U\&S commands, national agencies, and departments. We recommend using JSOC Terms of Reference as a possible model. We emphasize the need to 
examine historical data bearing on the USSOCOM legislation, former operations, experience such as JSOC and USCENTCOM, and problems requiring immediate resolution. Changes to the JCS assigned missions and functions or to the law itself may be necessary. We provide an outline of comparative relationships and potential problem areas. 
$\underline{\text { PAGE }}$

FOREWORD

EXECUTIVE SUMMARY . . . . . . . . . . . i

TABLE OF CONTENTS . . . . . . . . . . . . . . ix MISSION SUPPORT SYSTEMS . . . . . . . . . . . . . . 1

TITLE . . . . . . . . . . . . . 1

PURPOSE . . . . . . . . . . . . . . 1

OVERVIEW . . . . . . . . . . . . . . 1

CONCEPT . . . . . . . . . . . . 2

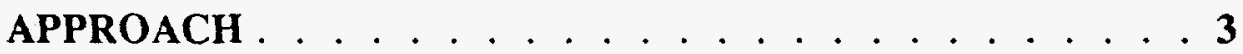

FEASIBILITY . . . . . . . . . . . . 6

RECOMMENDATIONS. . . . . . . . . . . 8

RESEARCH, DEVELOPMENT, AND ACQUISITION . . . . . . . . . . 11

TITLE . . . . . . . . . . . . . . 11

PURPOSE . . . . . . . . . . . . . . . 11

OVERVIEW . . . . . . . . . . . . . . 11

CONCEPT . . . . . . . . . . . . . 14

APPROACH . . . . . . . . . . . . . 14

FEASIBILITY . . . . . . . . . . . . . . . . . . 17

RECOMMENDATIONS. . . . . . . . . . . . . . 17 
TABLE OF CONTENTS (CONT)

PAGE

USSOCOM HQ EQUIPMENT . . . . . . . . . . . . . . . . . . .

TITLE . . . . . . . . . . . . . . . . .

PURPOSE . . . . . . . . . . . . . . . . . 21

OVERVIEW . . . . . . . . . . . . . . . 21

CONCEPT . . . . . . . . . . . . . . 23

APPROACH . . . . . . . . . . . . . . . . . . . . 24

FEASIBILITY $\ldots \ldots \ldots \ldots \ldots$

RECOMMENDATIONS. . . . . . . . . . . . . . . .27

C3I ARCHITECTURE . . . . . . . . . . . . . . . . . . . . . . . 29

TITLE . . . . . . . . . . . . . . . . . . . . .

PURPOSE . . . . . . . . . . . . . . . . . . . . . . . 29

OVERVIEW . . . . . . . . . . . . . . . . . . 29

CONCEPT . . . . . . . . . . . . . . . . .

APPROACH . . . . . . . . . . . . . . . . . .

FEASIBILITY . . . . . . . . . . . . . . . . . . . . 34

RECOMMENDATIONS. . . . . . . . . . . 35 
TABLE OF CONTENTS (CONT)

$\underline{\text { PAGE }}$

INTELLIGENCE DISSEMINATION. . . . . . . . . . . . . . 38

TITLE . . . . . . . . . . . . . . . . . . .

PURPOSE . . . . . . . . . . . . . . . . . . .

OVERVIEW . . . . . . . . . . . . . . . . . . . . . . .

CONCEPT . ..................... . .

APPROACH . . . . . . . . . . . . . . . 41

FEASIBILITY . . . . . . . . . . . . . . . 42

RECOMMENDATIONS . . . . . . . . . . . . . .42

TAB 1 OUTLINE FOR DEFINING USSOC INTELLIGENCE SUPPORT REQUIREMENTS . . . . . . . . . . . 44

TASKS TO BE ACCOMPLISHED . . . . . . . .44 TECHNICAL APPROACH. . . . . . . . . .45

INTELLIGENCE COLLECTION MANAGEMENT . . . . . . . . . .55

TITLE . . . . . . . . . . . . . . . . . . .

PURPOSE . . . . . . . . . . . . . . . . . . . .

OVERVIEW . . . . . . . . . . . . . . . . .

CONCEPT . . . . . . . . . . . . . . . . . . .

APPROACH . . . . . . . . . . . . . .60

FEASIBILITY . . . . . . . . . . . . . . .61

RECOMMENDATIONS . . . . . . . . . . . . . .62 
TABLE OF CONTENTS (CONT)

PAGE

INTELLIGENCE SUPPORT TO OOF TARGETING $\ldots \ldots \ldots$

$$
\begin{aligned}
& \text { TITLE . . . . . . . . . . . . . . . . . . 64 }
\end{aligned}
$$

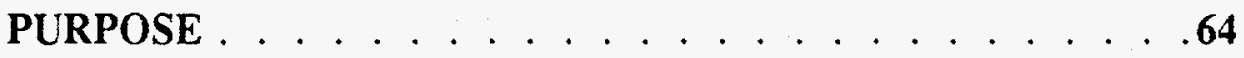

$$
\begin{aligned}
& \text { OVERVIEW . . . . . . . . . . . . . . . . . .64 } \\
& \text { CONCEPT . . . . . . . . . . . . . 67 } \\
& \text { APPROACH . . . . . . . . . . . . . . . . . . . . . .69 } \\
& \text { FEASIBLITY . . . . . . . . . . . . . .71 } \\
& \text { RECOMMENDATIONS . . . . . . . . . . . 71 }
\end{aligned}
$$

JOINT MISSION AREA ANALYSIS $\ldots \ldots \ldots \ldots$

TITLE . . . . . . . . . . . . . . . 74

PURPOSE . . . . . . . . . . . . . . . . . . . .

OVERVIEW . . . . . . . . . . . . . . . . .

CONCEPT . . . . . . . . . . . . . 78

APPROACH . . . . . . . . . . . . . 81

FEASIBILITY . . . . . . . . . . . . . . 81

RECOMMENDATIONS. . . . . . . . . . . . 81

xii 
JOINT SPECIAL OPERATIONS MASTER PLAN $\ldots \ldots \ldots$ TITLE . . . . . . . . . . . . . . . . . . . . PURPOSE . . . . . . . . . . . . . . . . . . . 84 OVERVIEW . . . . . . . . . . . . . . 84 CONCEPT . . . . . . . . . . . . . . . . . APPROACH . . . . . . . . . . . . . . . . . . FEASIBILITY . . . . . . . . . . . . . . . . . . . RECOMMENDATIONS . . . . . . . . . . . . . .

TAB 1 SUGGESTED FORMAT JOINT SOF MASTER PLAN. .94

BASIC PLAN . . . . . . . . . . . . . . . 94

"TYPICAL" ANNEX . . . . . . . . . . . . . 94

SUGGESTED ANNEXES. . . . . . . . . . . . .95 COMPARTMENTED ANNEXES (IF REQUIRED) . . . . . . . . . . . . . . . . . 96 


\section{PAGE}

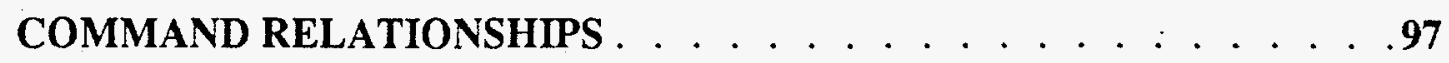

TITLE . . . . . . . . . . . . . . . .97

PURPOSE . . . . . . . . . . . . . . . . . . 97

OVERVIEW . . . . . . . . . . . . . . . . . . .

CONCEPT . . . . . . . . . . . . 100

APPROACH . . . . . . . . . . . . 101

FEASIBILITY . . . . . . . . . . . . . . 104

RECOMMENDATIONS. . . . . . . . . . . . . . . 104 


\section{TITLE: MISSION SUPPORT SYSTEMS}

2. PURPOSE: To examine SOF readiness requirements for logistic support--supply, storage, contracting, maintenance, and distribution--and recommend actions to develop effective mission support systems.

3. OVERVIEW: USSOCOM has the legislative mandate and JCS charter to train and equip SOF forces and to monitor SOF mission readiness. Readiness is directly dependent upon an adequate personnel support system, a good training base, and a responsive mission support system for logistics and related supporting functions: special storage, maintenance, re-engineering, secure and normal contracting, and facilities. The following sections address pertinent concepts, suggested approaches, and the feasibility of further development. The final section contains specific recommendations to assist USSOCOM in developing a multifaceted mission support system.

a. Background: The need for improved combat readiness is the driving factor underlying recent SOF legislation. Fully six years after the original Congressional direction and three years after supporting DOD instructions, adverse trends in readiness prompted a new Congressional mandate. The success of the new USSOCOM will be measured by improvements, or lack thereof, in SOF combat mission readiness. Mission support systems are a critical element in combat readiness. 
b. Baseline: The existing mission support systems of the three USSOCOM components--air, land, and sea--were created separately by the Services. They are neither standardized nor balanced with each other. The Navy SEALs, Army Special Forces, and Air Force SOF each has its own approach to acquisition and logistics and each has fundamental variances, achieved by waiver, from parent Service regulations. Further, each Service has applied separately for waivers to Federal Acquisition Regulations, and has established unique re-engineering requirements, special project storage, and support arrangements. None of this was done with a joint perspective.

4. CONCEPT: To correct this problem, USSOCOM must first develop a joint perspective on satisfying its mission support requirements. This must begin with a baseline identifying existing capabilities. Each of the components possesses both SOF-peculiar and common equipment items and a baseline of existing resources, including facilities and procedures. USSOCOM must catalog what is now available or programmed and determine the applicability of these baseline resources to the new joint mission. This must be an "across the board" scrub addressing all related areas (storage, re-engineering, contracting, crypto equipment, maintenance, communications, training, facilities, etc.). Although evaluation of quick reaction capabilities ( $Q R C)$ is specifically addressed in a separate paper on Research, Development, and Acquisition, QRC issues, in practice, will be equally important to USSOCOM logistics planning. For this reason, QRC resources, requirements, and systems must also be included in any baseline assessment of the USSOCOM mission support capability.

With the above in mind, USSOCOM must develop an accurate inventory of what today's SOF has on hand; how it was acquired; how it is issued and replaced; where it is stored; how it is moved; whether it meets all requirements, including joint 
requirements; whether it requires modification; when, where, and how maintenance is performed; and when, where, and how training is accomplished. Aside from assessing current capability to support the new joint command, this baseline review will help determine which of these support functions is being done well--or well enough at present--by the Services, and which, if any, should be an urgent priority for USSOCOM attention.

The status of MFP 11 will be key to establishing the USSOCOM mission support system. USCINCSOC control of MFP 11 will enable virtual "hands-on" direction of Service activities in support of SOF RD\&A and mission support requirements. Lack of direct USCINCSOC control, on the other hand, may result in "business as usual." It was "business as usual" which prompted the Congress to direct the creation of MFP 11 and establish USCINCSOC to play a direct and active role in resource management in addition to the traditional "CINC role" of requirements validation. The FY89-93 budget, which is being adjusted now, will be Service-controlled with USSOCOM monitoring MFP-11.

5. APPROACH: The first task must be to establish the baseline inventory. USSOCOM must work with the Services and the theater Special Operations Components to determine existing capabilities.

Next, USSOCOM should determine whether existing mission support capabilities can totally or partially satisfy joint mission requirements. Weak areas must be quickly identified and prioritized for corrective action, including starting all over again from scratch if appropriate. Once deficiencies are identified, USSOCOM must determine responsibilities for corrective action. Some problems will be SOF-specific, others 
Service-common. There may be some areas in which duplication of effort is appropriate, although this should be the exception rather than the rule. Clearly, USSOCOM will require help, particularly in the area of human resources, in evaluating what should be done and who should do it. USSOCOM should plan to tap directly into the Service major command organizations for supply and support systems. The Army Materiel Command, the Navy Supply Command, and the Air Force Logistics Command have large efforts and proportionate experience in mission support areas, including secure contracting, weapons and crypto equipment acquisition, and storage. These organizations usually handle re-engineering and quick response capabilities (QRC) as well.

In addition to relying on Service expertise, USSOCOM should expect to receive help in mission support concepts from both inside and outside the Department of Defense. Other agencies include the Defense Logistics Agency, the General Services Administration, the CIA, the NSA, the J-4 of the Joint Chiefs of Staff, and the many contractors supporting these agencies.

USSOCOM should also look to the mission support experience of the Joint Special Operations Command, which has established mission support arrangements with the Services. There will be good and bad ideas in all the concepts explored, but they should always be evaluated with the end goal in mind, improved and sustained combat readiness. In properly evaluating mission support capabilities, USSOCOM J-4 must fully understand the SOF role in the various war plans. The J-4 evaluation must consider the targets and timing of SOF participation in the Joint War Mobilization Plan (JWMP). Can mission support items be stored in theater? Do adequate support arrangements exist? If not, what arrangements exist to store equipment in CONUS and what 
procedures and resources are required to ensure timely deployment to engaged SOF units needing the equipment? The review must be sufficiently detailed to adequately assess existing facilities and the need to expand, supplement, or move to best meet SOF mission requirements.

Another facet of mission support which must be addressed is the Force Activity Designators (FAD) assigned to SOF units. There are units which currently have FAD 1 , the highest priority in the supply system. Other units may require similar priority, either permanently or until readiness ratings allow relaxing the priority. A FAD 1 priority may be required at the USSOCOM HQ as well, at least temporarily. Lessons learned in the development of the Rapid Deployment Force (now USCENTCOM) may provide historical lessons that apply to USSOCOM. In fact, it may be valuable to assess lessons learned from rapid establishment of complex organizations regardless of whether they might otherwise be considered "SOF-related."

A complicated aspect of mission support that USSOCOM must explore is support of indigenous personnel. Although there is confusion and contradiction over USSOCOM and its specific role in low intensity conflict (LIC), the command will certainly play an important role in this arena. Although the legislation may be ambiguous, various OPLANs have roles for SOF and indigenous personnel. When U.S. policy calls for support of indigenous personnel, be they "freedom fighters," irregulars, or special planning cells, SOF have often been involved; it is likely that SOF will be involved in the future. Indigenous or partisan support systems require certain generic as well as specifically tailored items. USSOCOM must be prepared to accommodate national programs with mission support equipment and training and, possibly, strategy and tactics. The command must maintain (either in theater or in CONUS secure storage) 
the basics required to sustain armed conflict. This includes small arms, ammunition, explosives, communications gear, packs, boots, rations, uniforms/clothing, transportation alternatives, maps, threat details, and many others items tailored to both theater and environment.

Following an initial look at mission support systems, USSOCOM must institutionalize its mission support process. Procedures must be established to evaluate, validate or reject, and act on requirements submitted by theater SOCs, Service components, and others. In USSOCOM, the "system" must be sufficiently flexible to monitor and respond to innovation among the troops if equipment does not do the job or a new idea will allow the job to be done better. The Services' validation process is complicated. It may be doubly so for USSOCOM. The command must also look at existing joint process and requirement review groups in order to model its own. As the process builds momentum, there may be valid requirements for additional manpower. Now is the time to aggressively pursue these manpower requirements. The $\mathrm{J}-1$ will depend on this process to identify personnel needs, and the J-8, J-4, or both must lead the way in validating requirements, evaluating program resources, and determining hardware and software requirements for USSOCOM.

6. FEASIBILITY: In view of its importance to the command, this area must be pursued vigorously. The risk lies in not investing the resources necessary to establish a viable and comprehensive mission support system. Further development is crucial to fulfilling the command's charter to monitor combat readiness and to train and equip SOF units. 
MFP 11, the most serious area of uncertainty, is key. This will be an ongoing problem until the debate over the control of resources and budgets is resolved. There is no consensus on USCINCSOC'S long-term role in the resources arena. There appears to be a clear difference of opinion between the Congress, which legislated USSOCOM management of MFP-11, and the DOD, which appears to support Service control of MFP-11. Regardless of the final outcome, USSOCOM must develop a capability to deal with the unique mission support requirements of SOF. Further, by establishing its requirements, USSOCOM may influence the debate in its favor, which will directly impact SOF combat readiness.

It is certainly feasible for USSOCOM to adequately research the many areas involved in establishing an effective joint mission support system. There is broad experience available within U.S. government channels to examine the tasks of contracting, re-engineering, providing secure storage, and maintaining and distributing supplies. Clearly, USSOCOM must approach mission support with a joint perspective and with combat readiness as the measure of effectiveness. It does no good for the SEALs or Special Forces teams to be ready if their aircraft are not combat ready. Conversely, combat ready aircraft are of little use if the SEALs and SF teams are unprepared. It is not feasible for USSOCOM to consider anything short of ensuring that SOF acquires the mission support system it needs to discharge its mission.

The process of analyzing war mobility planning to determine if force and equipment management will support the OPLANs is a major undertaking. The theater CINCs may not possess the war fighting capability they desire when all the pieces are put together. USSOCOM can provide an invaluable service by sorting out the many factors that comprise theater SOF operations. The reality of counting supplies in 
warehouses is crucial to warfighting. The mission support systems USSOCOM inherited are clearly disparate and may be seriously flawed in a joint context. The command must determine what it has to build on and what must be done first. The result will appear weekly in the unit reports on combat readiness, but the real measure will occur when SOF units deploy for action: either they will be well-served and ready, or they will lack what they need to fight and win.

7. RECOMMENDATIONS: The USSOCOM mission support system will be multifaceted, but it can be divided into three basic areas of concern. First, there are SOF-specific items for which USSOCOM should take full responsibility. This includes validating SOF requirements, programming manpower and resources, obligating MFP 11 funds, providing secure SOF contracting, re-engineering, distributing CONUS SOF equipment, and resupplying SOF items. Second, common items and other support should continue to be supplied by the Services to the components. These include major items common in the Service systems such as uniforms; some ammunition and weapons; aircraft development, acquisition, and modification; and some equipment-related training as appropriate. Third, there are items required for SOF support of indigenous personnel in foreign internal defense, war plans, or LIC environments. Although not yet fully defined, some of these will clearly fall under the USSOCOM umbrella.

The following recommendations will support development in all three areas:

a. The J-4 should establish a catalogued inventory of SOF equipment and how it is managed within each of the Services. A baseline is crucial to improving SOF mission support programs and developing a truly "joint" program. 
b. USCINCSOC should request Service, OSD, and JCS briefings and assistance in establishing logistics systems and priorities, validating requirements, programming resources, and funding. Without controlling these processes internally and externally, USSOCOM cannot perform its mission.

c. Following review of baseline data, USSOCOM should establish letters of agreement with Service chiefs of staff, describing in detail those mission support items which the Services must provide to the SOF. These agreements must establish a formal system that goes beyond personal arrangements to get the job done. They must address the complexities of MFP 11 today and how requirements will be met and funded in the future. The agreements must include services as well as equipment. Transportation of units and supplies in SOF war mobility plans must support the timetable of CINC war plans.

d. USSOCOM should request briefings from DLA, GSA, CIA, NSA, and other agencies or contractors dealing with secure contracting, re-engineering, special storage for weapons and crypto gear, maintenance, training, and normal and clandestine distribution. These items go to the heart of SOF business. USSOCOM must develop a staff that becomes expert in these areas if SOF capabilities are to be credible.

e. USSOCOM should develop a channel into the "black world" of clandestine procurement to determine where there are new items or procedures SOF can exploit. USSOCOM will not be able to fulfill its mandate to stay at the leading edge of technology, especially in the C3I world, if these channels are not opened. 
f. USSOCOM should explore the third category of SOF mission support to indigenous personnel, unconventional warfare, and low intensity conflict. The UW PROJECT STOCKS should be reviewed. It may be appropriate for USSOCOM to take over this effort. DOD and DOS, among others, will be interested in progress here. The mechanisms of the Counter Insurgency Support Office (CISO) should be studied and repeated in at least skeletal form.

g. USSOCOM should solicit direct contact with Service major commands for logistics and supplies. This should include briefings about how things operate now, how they need to be modified, and what things (secure contracting, re-engineering, $\mathrm{QRC)}$ can be done by or for USSOCOM.

h. USSOCOM should review existing logistics facilities and determine how to best integrate them into the SOF mission support system. This should include a review of the WMP and war plan requirements for SOF and its equipment. Failure to do this could result in active or reserve SOF units arriving in theater too late to perform required missions or without equipment to fight.

i. USSOCOM should review existing active and reserve unit reports of combat readiness to determine if mission support systems are effective.

j. Based on information obtained, the USSOCOM J-4 should recommend changes in FAD categories for critical equipment or units. 


\section{TITLE: RESEARCH, DEVELOPMENT, AND ACQUISITION}

2. PURPOSE: To provide USSOCOM with recommendations for developing a management and advocacy procedure to fund research, development, and acquisition (RD\&A).

3. OVERVIEW: In order to perform its newly legislated mission, USSOCOM must master the standard acquisition system and the PPBS at the same time it is learning all the unique details of development and procurement of SOF programs. USSOCOM must also develop a quick response capability $(\mathrm{QRC})$ system.

a. Background: Seven years ago, no formal R\&D program existed for the SOF. The budget consisted of daily operations and minor modifications programs, and the total SOF budget amounted to less than one-tenth of one percent of the DOD budget. There were only token acquisition programs across the Service budgets. The major emphasis on SOF/LIC came from the Congress, not from DOD. In spite of creating programs, emphasis, and appropriations for SOF, the congressional adds have not lifted the SOF budget and MFP 11 over one percent of the DOD budget, even in the highest years, FY88 and FY89. The in-fighting that has occurred between and within the Services has also strained working relationships among and within the staffs. USSOCOM must cope with this reality and quickly find a way to bring the Services together to support MFP 11. 
b. Baseline: In the existing programming and budgeting process, the Services run the Program Objective Memorandum (POM). The CINCs input an Integrated Priority List (IPL) and get to review Service POMs, the Budget Estimate Submission (BES), the Defense Resources Board proceedings, the Program Decision Memorandum (PDM), and the Program Budget Decisions (PBDs). These comprise SECDEF's input as his portion of the President's Budget (PB).

Each Service has its own concerns in response to the Defense Guidance, an important statement about priorities but not binding for program funding. USSOCOM must learn to use this system to ensure that planning and programming efforts are fruitful. USSOCOM's Washington Office, and the J-8, must track and influence the process at every step, including reprogramming among the four "money" committees in Congress. It will be nearly impossible to do this without strong representation resident in Washington. This is evident when one looks at the funds and programs USSOCOM inherited along with its charter.

MFP 11 includes extremely important programs for SOF's future. Some crucial direction came from efforts over the last five years from the OSD/(C3I) Special Operations Special Technology Division. Only their efforts to review, manage, and defend the SOF program during the annual SOF Congressional Budget Justification kept most procurement alive in both the white and the black programs.

The future survival of Service SOF programs will now depend on USSOCOM's ability to make tough decisions and negotiate delicate agreements with Service organizations for $R \& D$ and procurement. This is critically important and must be started immediately. For example, the Army's SOF aviation programs are in complete 
disarray as a result of confusion created by the poorly staffed Initiative 17 , one of 31 joint initiatives between the Army and Air Force Chiefs of Staff, in May 1984. The Congress refused to support the Army requests for MH-47E and MH-60X helicopters. As a result, Congress recently appropriated only $\$ 14 \mathrm{M}$ for further development of both of those aircraft. The Army must submit a progress report before going to full-scale development. No one really knows how many years behind the 1989 delivery schedule these programs are. On the other hand, Congress fully funded 42 PAVE LOW MH-53H/J which USAF had tried to give away.

In addition to rotary aviation, the fixed-wing programs, $\mathrm{CV}-22, \mathrm{MC}-130 \mathrm{H}$, and AC-130U, require close scrutiny. The programs total several billion dollars worth of TOA in MFP 11. All require management, development, continued procurement, support packages, test, and evaluation. The $\mathrm{MC}-130 \mathrm{H}$ was supposed to be an off-the-shelf program in 1981. The first aircraft will be delivered for test in November 1987, four years late. The CV-22 program has recently been slipped one year. The recent AC$130 \mathrm{U}$ contract is known to be underfunded by some $\$ 100 \mathrm{M}$. The level of detail required to provide program oversight is virtually incomprehensible to outsiders unfamiliar with the intricate procurement system.

The Navy Swimmer Delivery Vehicle (SDV) R\&D/acquisition is plagued by problems that rise out of limited Service support for small programs. After five years, there is still only one dry dock launch platform for current operations. Procurement of others is moving slowly. Development of an SDV with extended range and speed to make it a more effective asset is moving more slowly. These are the kinds of programs CINCSOC needs to energize with both more money and more attention. 
CINCSOC must develop a staff which is capable of detailed interaction with the Services. USSOCOM will be overextended if it tries to duplicate the major R\&D and acquisition systems of the Services, just as the Coast Guard found itself unprepared to handle "off-the-shelf" LU-25, H-65 procurement, competition, and contracts. Service procurement programs are complex, multilayered, and technical, requiring large numbers of qualified personnel on a continuing basis. Program details must be scrutinized whether buying uniforms, boots, weapons, ammunition, aircraft, boats, hardware, or software.

4. CONCEPT: USSOCOM must establish terms of reference or letters of agreement to interact with on-going Service efforts in MFP 11. Knowing who is responsible and where to get day-to-day details will be more realistic for the USSOCOM staff than handling program details.

Contact with defense contractors is an area which will require detailed involvement on the part of the USSOCOM staff. It is important for a staff element, probably J-8, to keep in touch with industrial development and technical breakthroughs that can be applied to SOF. The USSOCOM staff must cultivate a relationship with the Lockheeds, IBMs, Motorolas, GTEs, and other businesses that provide SOF equipment and services to remain aware of state of the art technologies which may benefit SOF.

5. APPROACH: USSOCOM must identify key areas to monitor and to influence in order to obtain the R\&D, procurement, and support it needs. A USSOCOM staff agency, such as the J-8 or JSOIC, must be responsible for keeping up with specific segments of this task. For example, if the $\mathrm{J}-8$ is organized into divisions responsible for the three areas above, the R\&D cadre should deal with the Army, Navy, and Air Force commands 
that do the $\mathrm{R} \& \mathrm{D} /$ procurement of current SOF programs and learn how they do business. The R\&D cadre must be cleared for access to classified procurement development and access other agencies such as DARPA, CIA, and others doing government work. The J-8 staff must thoroughly understand research, development, testing, and evaluation (RDT\&E) functions.

The USSOCOM cadre responsible for R\&D must know how and when to affect the RD\&A process which is normally divided into eight categories. The first category is pure research, such as the hypervelocity rail guns still in the lab. The next two categories are exploratory development and advanced development. The cadre must understand applications for such technology in all mission areas. By exploiting industrial and government contacts, USSOCOM can shape the direction of some programs and take spin-offs from others.

These first three $R \& D$ categories are followed by engineering development; management support; operational systems development; developmental test and evaluation (DT\&E); and operational test and evaluation (OT\&E). USSOCOM inherited a number of programs that exist within the eight categories above. The $\mathrm{MC}-130 \mathrm{H}$ COMBAT TALON II program is rapidly approaching the last two phases. This is four years behind schedule, something for which the Congress has annually called the Air Force to task. Now USSOCOM could become the "whipping boy." Consequently, USSOCOM must develop the expertise to track this program and others. The recommended approach is simple: fix what does not work, but do not build a new watch. The recommendations section of this document discusses what must be done to get on top of R\&D and acquisition and discusses contact with other agencies. 
As USSOCOM develops its command relationships, one of its most important interfaces will be the Defense Advanced Research Projects Agency (DARPA). DARPA is familiar with all aspects of RDT\&E. In addition, there is a SOF point of contact in DARPA's Tactical Technology Branch who has worked for years with the OSD/C3I Special Operations Special Technology (SOST) Division. DARPA knows SOF problems and speaks SOF language.

In addition to DARPA, there is another excellent source of talent and expertise in special $R \& D$ projects managed by the national laboratories. The national laboratories can apply superb scientific knowledge and a secure environment for "quick response" mission requirements. USSOCOM should consider the labs to be a valuable resource and work out a Memorandum of Agreement for their support. This process can be used to establish contacts, gain exposure, and educate both the USSOCOM and lab staffs about capabilities, methods, and missions.

OSD/C3I's SOST Division is another source of expertise and advice. It already monitors and partially funds nearly 30 joint projects for SOF. USSOCOM should work out a Memorandum of Understanding with OSD/C3I to exploit the expertise of that office. Some current SOST functions may be better accomplished by USSOC. OSD/C3I may be amenable to USSOC proposals in this area.

USSOCOM must closely monitor the FY88 Defense Authorization Bill and the proposed amendment by Congressman Hutto. The amendment would give USCINCSOC clear and full responsibility to direct MFP 11 funds. In addition, it would provide 120 authorizations for USSOCOM to manage RD\&A. It includes R\&D, program management, and administrative people to get USSOCOM functions established. 
6. FEASIBILITY: Although the law requires USSOCOM to manage MFP 11 (SOF program $R \& D$, procurement, and support), no unified combatant command can easily take on so many "tail" functions without affecting "tooth" requirements. The Services oppose USSOCOM management. In this area of development, acquisition, and support, USSOCOM must access existing expertise as much as possible. While exploiting existing expertise and systems, USSOCOM must speak the language, know whom to call for details, and understand how to influence the course of SOF programs involved. This is especially true this first year while the Services maintain management of MFP-11.

7. RECOMMENDATIONS: The following includes some events which will occur on a one-time basis. The USSOCOM legislation serves as the requirement for the minute level of detail involved. This list is critical to staff members in the $\mathrm{J}-8, \mathrm{~J}-2, \mathrm{~J} 3$, and $\mathrm{J} 4$, and the resource element of the WO. These recommended resource/management briefings must occur at the earliest possible date, even if there is no $\operatorname{ASD}(\mathrm{SO} / \mathrm{LIC})$ to participate. The ASD can later request similar briefings tailored to his staff needs.

a. USSOCOM should receive POM briefings on MFP 11 from each Service. The Service briefings should include the overall POM process within the PPBS: the schedule, the players, the office symbols and phone numbers. In addition to the overall look at the process, USSOCOM should request individual R\&D, resource, and logistics program managers, program element monitors (PEMs), and system program offices (SPOs) briefings on each and every SOF program included in the MFP, 11. This will take time and must include travel to locations where $R \& D$, support, and procurement events occur. 
b. USCINCSOC must request that an expert from DEPSECDEF's office and OSD/P, A\&E brief him on the current Defense Resource Board (DRB) process, schedule, and issues affecting SOF programs in this cycle. This should be a "friend in court" brief on the actual political process rather than a standard PPBS briefing. Although the ASD (SO/LIC) will sit on the DRB as the USSOCOM advocate, it may be some time before an ASD is confirmed. If FY89 adjustments are made without USCINCSOC involvement, MFP 11 may prove inadequate to meet USCINCSOC requirements.

c. USCINCSOC should request Service briefings on the several requirements studies done in the past three years defining the theater CINC SOF requirements. This affects current procurement, R\&D, and planned programs beyond FY93.

d. USCINCSOC should invite the chairmen of the four major military committees of Congress (HASC, SASC, HAC, SAC) to send staffers to discuss their views on the President's Budget. Particular emphasis should be given to SOF programs as line items at the program element level and below, if necessary. For example, the recent FY87 Supplemental funding package for DOD contained over $\$ 100 \mathrm{M}$ funding for PAVE LOW MH-53J helicopter modifications. It did not address Initiative 17 directly, but it gave the Army only $\$ 14 \mathrm{M}$ for its MH-47E and MH-60X R\&D. It did not address the requests for additional R\&D funds for the AC-13OU or acquisition funds for $\mathrm{MC}-130 \mathrm{H}$ programs. Both programs, major elements of the DOD plan for SOF air component capabilities, become unexecutable if the funds denied in the FY87 Supplemental are not included in the FY88 appropriation. The USSOCOM staff, especially before there is an ASD staff to help, must be responsible for information affecting execution of every SOF program. The "hill" staffers should prove useful in providing USSOCOM with such information. 
e. USCINCSOC should determine specifically how other CINCs have participated in the past in the POM process, and how they interface with the DRB and the Congressional committees. USCINCSOC should request CINC inputs regarding those SOF requirements now in MFP 11 and any requirements which should be included. This will parallel efforts in the Joint SOF Master Plan and Mission Area Analysis arenas. These discussions will present an opportunity to "market" SOF to the theater SOCs. The commanders or their representatives should be invited to sit in on the Service, OSD, and Congressional briefings to USSOCOM.

f. The law mandates that USSOCOM will keep up with the latest technology in C3I. USCINCSOC must establish a cadre within the J-8 to monitor technical developments that SOF can use. This staff element must take charge of monitoring industry, establishing industry contacts, requesting feasibility studies, and applying technical breakthroughs to SOF. As a starting point, this group should investigate those items identified at the annual meetings of the OSD/C3I Special Operations Special Technology Division. The charter of this staff element must include all types of communications, power, security, air/land/water transportation, navigation, materiel, weapons, ammunition, propulsion, night vision, electro-optical, and passive systems.

g. J-4 must track more than R\&D items. J-4 must monitor resource programming for logistics upkeep of SOF units to monitor the combat readiness of SOF in the CONUS and the theaters. The whole concept of quick response and acquisition is critical to SOF organization and management. USCINCSOC should invite briefings from the Services, DARPA, and other special acquisition and quick response organizations. The briefings will illustrate both the short- and long-term requirements of SOF while educating and organizing the staff. Air Force Reg 800-29 and similar documents on 
QRC from Army and Navy black world RD\&A should be included. USSOCOM should develop a strategy for obtaining maximum advantage from these programs yet not limit QRC to these modes only. Further, USSOCOM should rapidly become aware of theater LIC requirements in this area.

h. USSOCOM should determine whether the ASD staff or the WO can handle program resources management above Service level. The continuity of civil service personnel is very desirable, and avoiding Service-level resource competition is a huge advantage.

i. Clearly, USSOCOM should not undertake to duplicate or supplant valuable Service RD\&A functions. Rather, CINCSOC should place primary emphasis on developing a complementary RD\&A effort which will directly support Service efforts while ensuring detailed interaction and oversight where appropriate. 


\section{TITLE: HEADQUARTERS EQUIPMENT}

2. PURPOSE: To recommend actions to identify the USSOCOM requirements for information systems.

3. OVERVIEW: The unprecedented and rapid establishment of USSOCOM, the decision to disperse USREDCOM responsibilities and functions, and the selection of MacDill AFB as the location of USSOCOM headquarters are among the many factors which influence USSOCOM's equipment needs. One of the most basic challenges is determining the information systems hardware and software requirements required by the headquarters to support the command's newly assigned missions, functions, and responsibilities. With its worldwide mission, USSOCOM must communicate and interact with an exceptionally broad range of military and non-military entities. Moreover, unlike USREDCOM, USSOCOM must be equipped both to deal with urgent real-world operations and to support special operations in peacetime. Additionally, OPSEC, COMSEC, deception, while important to USREDCOM, are absolutely vital to USSOCOM.

a. Background: The JCS decision to locate HQ USSOCOM at MacDill AFB, Florida, was supported by assumptions that in-place USREDCOM facilities, equipment, and communications would facilitate earliest readiness of the new command. While that assumption is correct, particularly when compared with "starting from scratch," the systems inherited from USREDCOM are incomplete and inadequate for USSOCOM needs. For example, recent incidents in the Persian Gulf, which required intensive communications between USCINCCENT to forces in his AOR, quickly saturated existing KY-3 trunks--without significant USSOCOM operational use. If USSOCOM and USCENTCOM were to require simultaneous access to the limited number of lines now 
available, there would be an inevitable and unacceptable breakdown in secure communications to the detriment of both commands. Information systems resources can and should be managed smartly; however, it may be a false economy to imagine that the extraordinary co-location of two major combatant commands at a single installation will not require extraordinary redundancies in terms of equipment, maintenance, and manpower resources if both commands are to be served well.

b. Baseline: There are many deficiencies in existing capabilities at MacDill; however, it is generally agreed that the most serious shortfall is in secure voice (KY-3). Currently, there are only 20 trunk lines with 80 total drops available. While this number may be adequate for a single headquarters, it is not capable, even on a routine basis, of handling traffic from two unified combatant commands and a functional Air Force base. There are requirements for datafax, facsimile, and other imagery transmission requirements as well.

There are numerous requirements for secure voice communications, including Redswitch lines within the USSOCOM building and commercial Blackswitch (STU-2 or -3) for all telecommunications. Even unsecured AUTOVON is seriously deficient. An on-going survey at MacDill AFB shows only 90 trunk lines: 35 lines in, 35 lines out, and 20 two-way lines. During peak periods on normal work days, the system is routinely saturated. Normal usage levels do not compare with USSOCOM requirements for support to a contingency operation. Doubling the current capability would still 
fall short of meeting the requirement. This serious shortfall must be addressed quickly, methodically, and realistically to support USSOCOM wartime and crisis missions and functions.

An on-going C3 architecture study by the Institute for Defense Analysis and the Special Operations Command and Control System Master Plan both identify requirements for vastly expanded encrypted radio, microwave, and electronic message capabilities. USSOCOM must have equipment that is compatible with its forces, the theater SOCs and national networks.

4. CONCEPT: A number of communications and information flow planning issues must be addressed. A first step must be to examine the nature of the command and its responsibilities, both in comparison to the joint command it "replaces" (USREDCOM responsibilities and headquarters equipment) and in relationship to its assigned force structure and those forces' information systems infrastructure. What addtional requirements have been generated by the creation of USSOCOM?

a. Comparison to USREDCOM: Differences in mission between USREDCOM and USSOCOM indicate a stronger USSOCOM emphasis on secure communications. The nature of SOF crisis response operations requires increased capacity to accommodate the volume of secure traffic associated with crises.

Additionally, USSOCOM's responsibility as a supported command requires not only increased capacity at MacDill, but also a capability to support deployed headquarters 
operations. Inherent in this requirement is the ability to interface securely and directly with all theater commands, the forward elements of several other government agencies, and deployed forces whether assigned or "chopped."

b. New Requirements: Prior to establishment of USSOCOM, a joint SOF command structure was notional. Theater commands maintained small cadres of personnel to be augmented as required to execute special operations under existing war plans. In garrison, CONUS SOF had no permanent infrastructure. Moreover, joint training and exercise requirements were met by assembling Service participants (often supported by the USREDCOM's Joint Special Operations Support Element (JSOSE) prior to 1983). The Joint Special Operations Agency and its predecessors were limited by charter to staff functions at the OJCS level.

USSOCOM is the first permanent headquarters charged with responsibilities for training, equipping, exercising, and employing joint SOF. As the command matures to fully operational status, each of these mission areas must be supported by reliable, interoperable, and secure communications, data transfer, storage systems, and equipment. During the transition period, USSOCOM must assign first priority to the most critical of its responsibilities--employment.

5. APPROACH: It is important to establish a baseline of requirements and current capabilities. It may be useful to categorize information processing needs as either operational--time-sensitive and highly secure--or supporting--less timely and less secure--with relatively constant volume.

- Operational requirements include readiness status reporting, mission and other operational planning, mobility tailoring, operational support coordination/tasking, $\mathrm{C} 2$ and intelligence. 
- Supporting needs include training, equipment acquisition, long-term planning, etc., and are much more conducive to workarounds and transitional arrangements.

Clearly, USSOCOM headquarters does not have the communications equipment to meet requirements for rapid, secure, high-volume communications in a crisis. The question that must be asked is "how much is enough?" Sizing must be based on "worst case" demand. Relevant past experience, e.g., Grenada, offers useful qualitative guidelines, but lessons learned do not establish precise quantitative boundaries. For example, we know that secure telephones were swamped at more than one headquarters, but we also know that the next crisis almost certainly will be different in scope and intensity. The question of "how much" must be based upon future considerations, not on past performance data.

In building its required capabilities, USSOCOM must depend on existing capabilities in military communications and on programmed improvements in the state of the art. The Worldwide Military Command and Control System (WMMCCS), AUTODIN, AUTOSEVOCOM, and AUTOVON systems, and planned improvements such as the Special Operations Information System (SOIS) and meteor burst HF radio specially tailored for specific users, are baseline systems which USSOCOM must fully understand. The existing Intelligence Data Handling System (IDHS) in the USSOCOM building is an example of a mature intelligence system available to USSOCOM. DODIIS compatibility standards and related communications architectures are important issues which bear directly on USSOCOM needs. Some important baseline information on current capabilities will be compartmented for security reasons. Identifiying and evaluating these capabilities will be more difficult. TENCAP systems, the fleet FIST systems, and the PIRATE system are in this category. 
One approach to assessing requirements may be development, exercise, and evaluation of a worst case scenario which strains the current capabilities to the point of breakdown (mission degradation). Such a scenario envisions NCA tasking USSOCOM as a supported command; simultaneous tasking of JSOC; rapid buildup and deployment; and a scenario location which is also challenging to State, CIA, DMA, and other agencies. It would further require short notice, significant airlift and tanker support, and both national- and theater-level reconnaissance and intelligence requirements. Each element of Headquarters USSOCOM must be challenged to do its job in an unstable mission planning environment created by a rapidly changing political scenario.

An exercise of this type would quickly identify critical nodes and highlight information processing systems and equipment shortfalls which directly influence employment success. A corollary benefit would be identification and analysis of command relationships which break down because of procedural or equipment incompatibilities.

6. FEASIBILITY: Several factors complicate the process of analyzing HQ USSOCOM equipment needs; they are:

- Lack of definition of USSOCOM's supported command role and requirements.

- Unique demands (reflecting highest national interest, time sensitivity) for intelligence, mission planning, data retrieval, and communications.

- Competition for shared systems/equipment with another combatant command, with a significant probability of concurrency in peak demands.

A tightly developed, well-focused worst case scenario exercise is feasible as a means to adequately assess HQ USSOCOM's equipment needs. 
7. RECOMMENDATIONS: USSOCOM should perform a near-term survey of known and estimated requirements and a concurrent evaluation of worst case needs.

a. Form a "Tiger Team" to address headquarters equipment needs. Recruit SOF operational expertise from components to help form the team.

- Establish an inventory and baseline of existing and programmed equipment at USSOCOM.

- Survey requirements for operations, intelligence, logistics, planning, and other headquarters functions.

- Review lessons learned by JSOC and USCENTCOM during their formation. Examine compatibility with component headquarters and SOF unit equipment. Include overseas units and the theater SOCs as well as Navy fleet commands.

- Form an intelligence committee headed by the J-2 to review requirements for connectivity to national-level intelligence systems and agencies. Address lessons learned during Grenada, Achille Lauro, and other crises in which other agencies, e.g., the State Department, played lead roles but used incompatible equipment. Work issues into the on-going Theater Intelligence Architecture Program (TIAP), the C3 study, and the Special Operations Command and Control Systems Study. Be sensitive to the on-going President's Report if communications, command, control, or equipment deficiencies are mentioned.

- Assess the requirement for USSOCOM to communicate with SOCs and deployed SOF units. Identify equipment that is compatible with programs to improve deployed SOF connectivity from a joint perspective as either a supported or a supporting CINC.

- Review requirements at MacDill and potential relocation sites for mobile equipment required for emergency relocation. Address air, sea, and land en route requirements.

- Report recommendations to USCINCSOC as appropriate. Submit a report of requirements for short- and long-term improvements within six months. 
b. Conduct a "worst case" command post exercise to saturate the USSOCOM network with operational, intelligence planning, and logistical requirements at all levels of command. If possible, work simultaneously with USCENTCOM to evaluate the existing MacDill systems. Use results to help determine long-term equipment needs. Work with USCENTCOM to obtain improvements. 


\section{TITLE: COMMAND, CONTROL, COMMUNICATIONS, AND INTELLIGENCE ARCHITECTURE}

2. PURPOSE: To identify characteristics of a C3I architecture to assist USSOCOM in rapidly achieving operational links to selected units, organizations, and agencies.

3. OVERVIEW: This paper examines the communications and intelligence aspects of the developing USCINCSOC C3I architecture. It further discusses command and control requirements for support to readiness functions such as training, equipping forces, and monitoring combat readiness of SOF units assigned to theaters.

Background: The legislative mandate to form the USSOCOM is focused on unity of command. Special operations have frequently broken down due to failures in communications links and blurred lines of authority. Other contributing factors have included misunderstood priorities, cumbersome procedures, and incompatible equipment. For example, U.S. forces, not just special forces, have a variety of incompatible radios. This most basic communications link, which should be common among all forces, was a direct cause of fatalities at Kotang Island during the Mayaguez "rescue." Clearly, successful command and control depends upon effective and interoperable communications equipment, procedures, and systems.

USSOCOM faces a number of significant command and control issues involving its Service component. The Navy SEALs remain completely outside the USSOCOM structure. The communications and intelligence links required to support SEAL team requirements, should USCINCSOC be directed by the NCA to perform a mission, cannot be clearly defined. The Air Force component includes more non-SOF units and people than special operators. The relationship of USCINCSOC to those non-SOF units is 
ambiguous; their presence dilutes the support of his air component commander. One of the most serious command and control problems in this dual-hatted arrangement is the Air Force's refusal to recognize that special operations low level (SOLL) aircraft now belong to USCINCSOC in accordance with JSCP Annex E and the law. The question of how USSOCOM provides those forces with required intelligence and planning information, and indeed how USSOCOM controls these forces at all, is an issue of immense significance to USCINCSOC. Similar confusion exists within elements of the Army 1st SOCOM. How will USSOCOM task support planning and programming, or employ elements of ARSOC such as the aviation battalion, the signal battalion, or other support elements? Does USSOCOM require C3I connectivity with these units or not? It is important that USSOCOM aggressively address these basic command and control issues now.

b. Baseline: USSOCOM is both a supported and a supporting command. As a supporting command, USSOCOM provides trained and equipped SOF to theater commands which employ the forces. The USSOCOM C3I architecture must address the need for interoperable equipment and working communications channels serving critical intelligence and operational control nodes. The same C3I architecture must serve USSOCOM as a supported command when SOF is employed in operations directed by the NCA. In this role, USSOCOM must communicate with deployed active and reserve units, theater commands, Service components, and national agencies. Additionally, USSOCOM missions and functions include day-to-day responsibilities that require routine communications channels to the above units, commands, and agencies. 
Existing capabilities inherited from USREDCOM are inadequate to handle the volume and type of traffic required. These include AUTOVON, AUTODIN, AUTOSEVOCOM, Intelligence Data Handling System (IDHS), INDICOM, WWMCCS, CRITICOM, and other radio/telephone links which will be saturated in a crisis. Furthermore, automated mission planning systems and the data and communications resources they require are not deployed and cannot be supported within current capability.

There are valid requirements for expanded and improved secure voice communications, including Redswitch lines within the USSOCOM building and commercial Blackswitch (STU-2 or -3) for all telecommunications. Even unsecured AUTOVON is seriously deficient. An on-going study at MacDill AFB reveals that there are only 90 trunk lines: 35 lines in, 35 lines out, and 20 two-way lines. During peak periods on normal work days the system is routinely saturated and routine operations do not begin to reflect the requirements for support of contingency operations. A conservative estimate indicates that doubling the existing capability may still fall short of meeting requirements. This is a serious shortfall which must be addressed quickly, methodically, and realistically.

The on-going C3 architecture study by the Institute for Defense Analysis and the Special Operations Command and Control System (SOCACS) Master Plan both identify requirements for encrypted radio, microwave, and electronic message capabilities. USSOCOM must have secure, reliable, and redundant capabilities compatible with its forces, the theater SOCs, and national networks. 
4. CONCEPT: USSOCOM needs a C3I architecture addressing its role as either a supported or a supporting command. The command must disseminate intelligence and operational information for mission planning, exercising, and execution of assigned tasks. The system must access, analyze, and distribute information from national agencies and command centers to critical nodes, including operational units deployed and in action. The architecture must address personnel needs, organizational structure, communications equipment, and command arrangements that support USSOCOM roles in peace, war, or contingency operations.

USSOCOM cannot rely on the overburdened communications lines that are shared by the U\&S commands today. The requirement to respond to NCA orders as a supported command mandates a system that is capable of reaching all critical levels within the severe time constraints that normally accompany special operations. In addition to these significant requirements for timeliness and sufficiency, USSOCOM must have equipment which ensures that information can be passed to forces in hostile territory without fear of intercept or detection.

5. APPROACH: USSOCOM should develop its C3I architecture in two phases and take advantage of efforts already underway. Phase One includes analysis of existing and programmed SOF C3I equipment, organizations, personnel, command relationships, points of contact, and lines of authority. The scope of the analysis should range from the top of the chain of command -- the President -- to the forces in the field.

- Ensure that personnel and SOF points of contact in various intelligence, communications, and operational units are aware of the information they are to provide and how it gets into the network.

- Identify organizations and individuals responsible for specific mission support to intelligence, operations, logistics, and command in peace or war. 
- Identify the specific channels and timetables that information must meet to ensure connectivity among planners, support functions, operators, and commanders in all operational environments.

- Determine equipment needed to provide data, facsimile, voice communications to deployed units needing the information.

- Identify shortfalls.

Some of this is already underway through the JSOA contract with the Institute for Defense Analysis (IDA), which is developing a SOF C3 architecture. It must be noted, however, that this contract does not address intelligence issues. Command and control communications systems must be compatible with intelligence support systems. The IDA contract deals with command and control communications exclusively.

Phase Two should address shortfalls and analyze systems currently programmed to improve SOF C3I. In addition to several efforts by the individual Services to provide their components with reliable, interoperable communications, other efforts apply directly to SOF C3I. For example, the JSOC Special Operations Intelligence System (SOIS) offers connectivity with components and theater commands. The long-term follow-on program, the Special Operations Command Research Analysis and Threat Evaluation System (SOCRATES), is developing an architecture to address concepts, systems, and connectivity among USSOCOM, theater commands, and national agencies. This effort is under contract in the Theater Intelligence Architecture Program (TIAP).

These efforts will form the basis for short- and long-term programs. Some of the information systems required will be dependent upon developing command relationships. USSOCOM must take the lead in resolving questions concerning lines of authority and control. For example, USSOCOM must determine its role in supporting the ASD(SO/LIC) in low intensity conflict (LIC) environments. This requires validation of requirements 
and development of special channels with the Department of State, national intelligence agencies, and even foreign governments.

The question of command and control relationships is key. Some would contend that the United States has a long history of performing poorly in contingency operations. The joint Service system converts slowly and inefficiently from peacetime structures to warfighting. Overcoming this same tendency may be the command's biggest challenge.

USSOCOM must specifically address the role of JSOC as a potential standing Joint Task Force (JTF). Naming the JSOC as a standing JTF to deal with contingency operations and as a focal point for LIC will dilute JSOC's ability to perform its assigned mission. USSOCOM may choose to form a cadre to direct JTF operations, but JSOC should not.

Many C3I links require redundancy and there will be a need for duplication. It is likely that JSOC will be called upon to perform its mission at the same time a JTF is formed to address crises in the Middle East or Southwest Asia. Neither a JTF nor JSOC will have the time, the resources, or the expertise to perform both missions simultaneously. Their equipment requirements may be identical, but they should remain separate entities to be individually effective and mutually complementary.

6. FEASIBILITY: It is both feasible and desirable that USSOCOM focus on the on-going contracts with IDA (C3) and with Betac (TIAP). The two efforts are complementary and will establish the USSOCOM connectivity requirements with the 
NCA, component units, national agencies, and theater commands. Importantly, effective communications channels to the $\mathrm{ASD}(\mathrm{SO} / \mathrm{LIC})$ staff must be developed as soon possible.

7. RECOMMENDATIONS: As described above, there are a number of important facets to the USSOCOM C3I architecture. In the short term, USSOCOM must depend upon existing Service and theater command channels to provide communications and intelligence. Memoranda of agreement establishing these relationships should be negotiated immediately. Equipment and systems are available off the shelf to provide the short-term connectivity needed for intelligence support, mission planning, and operational communications. Long-term solutions depend on resolving significant command and control issues and focusing on research, development, and acquisition programs to meet SOF needs for preparation and employment connectivity. The following specific recommendations apply:

a. Assign experienced SOF personnel to help define USSOCOM command, control, communications, and intelligence requirements. If the command cannot accelerate assignment of SOF-experienced personnel, USCINCSOC should request temporary but extensive support from the Services and joint commands.

b. Examine existing C3I architectures and infrastructures for possible application to USSOCOM requirements.

c. Examine architecture requirements from both a fixed and a mobile headquarters perspective. USSOCOM must have connectivity from virtually any location to any other location which may employ SOF units. There are several mobile or transportable 
communications and/or intelligence systems available off the shelf, including PIRATE (classified), Interactive Television Company's FULCRUM, and Lockheed's Strategic/Tactical Automated Mission Planning System, which have direct USSOCOM application to the USSOCOM C3I problem.

d. Identify all organizations and specific personnel responsible for communications and intelligence support to SOF mission planning, monitoring, and execution.

e. Document requirements for connectivity between these organizations and USSOCOM.

f. Clear appropriate USSOCOM staff personnel into JSOC compartments. Explore the parallels and differences between JSOC and USSOCOM needs in the C3I arena. USSOCOM will not wish to duplicate the JSOC intelligence structure, but there are perhaps more similarities than differences in requirements.

g. Investigate the requirements for a standing SOF Joint Task Force. There is little doubt that the nation needs a permanent crisis cell or JTF to perform the critical SOF function. On the other hand, a JTF that stays "geared up" for conventional and unconventional force employment cannot specialize in a sub-mission area such as counterterrorism. For this reason, we do not believe that JSOC should be considered a standing JTF.

h. Examine the IDA C3 contract and the Betac TIAP contract for cross-fertilization of ideas and possible acceleration of effort. 
i. Review short-term C3I equipment needs. Focus on off-the-shelf equipment that can help immediately.

j. Assign staff action to stay abreast of emerging technology that will assist USSOCOM intelligence, communications, and operations planning and execution. Develop short- and long-term recommendations for program action.

k. Present all appropriate data in a matrix format showing USSOCOM as both a supported and a supporting command.

1. Require monthly reviews of C3I planning and equipment status to USCINCSOC until the command is up and running at full speed.

m. Review contradictions among JSCP Annex E forces assigned to USSOCOM. Identify critical issues which affect command and control of each component. Prioritize issues, develop strategies, and, if required, involve USCINCSOC personally to resolve.

n. Sponsor a theater conference to determine how the SOCs currently handle command, control, communications, and intelligence. Determine shortfalls and draw on strengths to develop short-term strategies for C3I support to both theater SOC and USSOCOM support requirements.

o. Conduct command exercises to saturate the system and realistically test C3I capabilities in a crisis response mode. 


\section{TITLE: INTELLIGENCE DISSEMINATION}

2. PURPOSE: To examine USSOCOM intelligence dissemination requirements and recommend actions to develop effective intelligence dissemination systems.

3. OVERVIEW: Intelligence dissemination is the process of moving intelligence information from the collector, through analysis and processing, to the end user. Dissemination of intelligence data and finished products has traditionally depended upon fairly conventional methods, including hardcopy documents, General Service Communications (GENSER) and Defense Special Security Communications System (DSSCS) messages, analyst-to-analyst communications, internal and external database access, verbal (voice) communications, and exchange of other written communications. These current dissemination methodologies and capabilities do not fully satisfy USSOCOM requirements for rapid, reliable, and secure dissemination of intelligence during the planning and execution of special operations. The unique mission of USSOCOM and the manner in which special operations are conducted require new and innovative approaches to the dissemination problem.

a. Background: A Draft Operational Concept paper prepared by members of the USSOCOM staff in August, 1987, presents a valid overview of the operational requirements that drive the need for timely and tailored intelligence support. The following excerpts from that paper help place these requirements in perspective:

- "Equipment and procedures must have the capability to operate within and among Services to achieve the highest degree of interoperability."

- "Joint special operations forces must be capable of transmitting and receiving secure communications without being detected." 
- "Special operations forces require the greatest access possible to all sources of intelligence..."

Virtually every mission statement in the draft paper includes requirements for timely, reliable, and secure capabilities to exchange intelligence information between USSOCOM forces and a variety of U.S. and foreign elements, both military and civilian.

b. Baseline: USSOCOM's baseline intelligence dissemination capabilities are scant, but will continue to evolve as Intelligence Data Handling System (IDHS) components from the disestablished Readiness Command migrate to the USSOCOM and as other equipment and systems are added to the USSOCOM inventory.

"In garrison" systems, for the most part inherited from USREDCOM, include both internal and external interfaces to support the flow of intelligence into and out of USSOCOM. There are several existing interfaces between the USSOCOM IDHS and external elements:

- AUTODIN is used to support the transmission and receipt of record communications traffic. It supports receipt and transmission of both GENSER and DSSCS messages. The interface to the USSOCOM ADP (AN/GYQ-21V) system is via a dedicated message processing system referred to as the Communications Support Processor (CSP). CSP is the current DODIIS standard for AUTODIN message processing support.

- INDICOM is an analyst-to-analyst communications capability supporting interactive and message communications between analysts at different locations. It is a part of the DIA I\&W network.

- An AIRES Interface allows USSOCOM intelligence analysts to directly access the AIRES database located in the Washington, D.C. area.

- An IDHSC-II interface supports access to external databases at DIA and NSA, principally DIAOLS/COINS. 
- OPSCOMM circuits support interactive and message communications between USSOCOM communications, operations, and intelligence analysts at distant locations.

- The "in garrison" IDHS interfaces electronically to the USCENTCOM IDHS to support local exchange of intelligence between the two commands.

In addition, USSOCOM uses secure voice telephone to discuss classified topics with persons at distant locations. The command also possesses a limited quantity of secure voice communications devices to support operational RF communications requirements.

4. CONCEPT: SOF planning and execution must respond quickly to "fast moving" political and military events which frequently defy prediction. Often, there is very little time between recognition of the need for SOF action and actual execution of a special operation. During that brief interval, USSOCOM, either supporting a theater CINC or acting as the supported force, must plan the operation and deploy forces. Success depends greatly upon the timeliness and validity of critical intelligence information provided to USSOCOM planners and operational forces. Meeting such stringent timeliness criteria depends directly upon the systems and methods employed to disseminate the intelligence information.

Significantly, USSOCOM consists of permanently assigned organic assets and components of the various Services that will "chop" to USSOCOM or to another CINC during exercises and execution of operations. Land, sea, and air forces require intelligence support while based in static sites (in garrison), while en route and deployed to forward operating areas, and while executing missions in hostile territory. The highly mobile, fast-strike character of special operations demands effective 
interoperation of the components during both the planning and execution phases of operations and requires common access to valid, reliable intelligence information by all components.

Combining the special operations capabilities of several Services under a single command also offers an opportunity to combine common intelligence support requirements that have been treated separately in the past. Further, as the Joint Studies Analysis Group (JSAG) continues its effort to develop a Joint Operations Concept Statement, there is a definite need to examine the total intelligence support concept of the USSOCOM, to include intelligence dissemination requirements.

5. APPROACH: With the above in mind, it is vital to gain a perspective on the broad nature of USSOCOM intelligence requirements before focusing specifically on how the intelligence is going to be distributed. USSOCOM must identify the specific intelligence support requirements of each organization, describe the requirements in terms of data content, timeliness criteria, relative importance, periodicity of update, most probable source, form or format of data, and such other information as may be appropriate to support a requirements validation effort.

Once broad intelligence support requirements are determined, USSOCOM should develop a detailed baseline of current and planned collection, processing, and dissemination capabilities for comparison with the overall requirements of the new command. This comparison will identify strengths and deficiencies and provide a basis for planning and acquisition actions to achieve the required intelligence capability, including dissemination. The question of dissemination issues will then focus on two broad categories: 
- Those organic USSOCOM communications and ADP capabilities needed to satisfy global operational requirements.

- Those policies and procedures necessary to ensure cooperative and effective access to resources available through our allies, embassies, other military organizations, and national agencies.

To determine the total USSOCOM intelligence support requirement, a number of major tasks must be performed, including data collection, analysis, and documentation; independent review and verification; and final USSOCOM validation.

Tab 1 provides a detailed discussion of methodology to determine intelligence support requirements.

6. FEASIBILITY: The TIAP process now underway will provide a long-term answer to the crucial questions raised in the above discussion; however, it is both prudent and feasible to address these issues in the short term as well. A sharply focused analysis in the short term will assist in developing the broad guidance needed immediately and will feed directly into the ongoing TIAP development of a conceptual architecture for USSOCOM intelligence support.

7. RECOMMENDATIONS: The following recommendations will assist the command in determining intelligence dissemination requirements:

a. Define the total USSOCOM requirement for intelligence dissemination support. This will first entail defining the command's requirement for intelligence information. Use the detailed outline at Tab 1 to plan this effort. Include requirements related to exercises, training, planning, and actual execution of special operations. Do not neglect the capability needed to support "day-to-day" operations. 
b. Develop a detailed baseline of current and planned intelligence dissemination capabilities.

c. Analyze and compare requirements versus existing and planned capabilities. Identify and prioritize weaknesses and deficiencies.

d. Perform a concurrent assessment of existing and emerging technologies and systems for possible application to USSOCOM requirements.

e. Develop a prioritized set of recommendations for correcting weaknesses and deficiencies for USSOCOM senior staff approval. Prepare a plan for correcting the shortfalls based upon the priorities established.

f. Develop the necessary PPBS documents to establish a formal procurement effort to acquire the required capabilities.

g. Capitalize upon ongoing efforts (particularly TIAP) throughout this process. Attempt to accelerate the TIAP schedule, or initiate other tightly focused efforts to provide as much data as possible in the near term. Determine whether other programs (such as INCA) can adequately address the near-term requirements of USSOCOM. 


\section{TAB 1}

OUTLINE FOR DEFINING USSOC INTELLIGENCE SUPPORT REQUIREMENTS

\section{TASKS TO BE ACCOMPLISHED:}

a. Data Collection

- Objectives

- Plan

- Aids

- Collection

- Correlation and reduction

- Documentation of results

b. Requirements Analysis and Documentation

c. Requirements Review and Verification

d. Final Requirements Documentation

e. Final Requirements Validation 


\section{TECHNICAL APPROACH:}

a. Data Collection:

Develop Data Collection Objectives: The broad data collection objective is to collect sufficient information to determinate the intelligence support requirements of all USSOCOM elements. The data collection objectives related to the components should be driven only by those requirements that directly affects performance of missions in support of the USCINCSOC. All data collection efforts must:

- Accomplish data collection with minimal disruption or interference to on-going operations, and

- Use data collection resources in a way that ensures a high probability that all objectives will be met.

Establishing specific data collection objectives is dependent upon the knowledge of the data collection team. If team members are intimately familiar with the USSOCOM organization, mission, and OPLANS, the collection objectives can be established with very little preliminary research. If not, a preliminary research effort is required to determine SOCOM organizational structure, mission, and supporting forces; command and control structure; operations plans; command relationships with theater CINCs; and interoperability requirements.

Interviews and document research are among the techniques most useful in this initial research effort. These techniques require direct contact with USSOCOM personnel and access to various documents or databases. The data collection "cycle" includes: 
- Establishing initial data collection objectives

- Establishing a schedule for accomplishing initial data collection

- Coordinating the initial effort with organizations to be visited

- Accomplishing initial data collection

- Correlating and reducing collected data

- Analyzing data as required

- Documenting the results of the data collection effort

- Identifying data deficiencies or "gaps"

- Collecting additional data, if necessary.

Knowledge of the command should now be sufficient to establish a finite set of specific data collection objectives and to develop a data collection and analysis plan. Objectives should be stated in concise (often single sentence) format. They provide the basis for the data collection plan and actual data collection, and represent the criteria against which the success of the data collection effort will be judged.

Develop Data Collection Plan: The data collection plan should address the following topics:

- Performance schedule

- Personnel schedule

- Locations and organizations to be visited

- Data collection techniques to be employed

- Data correlation and reduction methodology 
- Analytic methodology

- Tools, equipment, and aids to be employed

- Special requirements and considerations.

Develop Data Collection Aids: Almost all data collection efforts employ some form of data collection aids. The specific aids are usually dependent upon the data collection techniques used. The most common techniques to be used in determining USSOCOM intelligence support requirements are interviews, research of documents, and other forms of data, observation, and questionnaires.

Each technique demands specific types of data collection aids to execute the effort efficiently and effectively. Interviews, for example, require prior preparation of a form that outlines the specific topics to be addressed and questions to be asked and a media for recording the findings of the interview (may include magnetic media in some cases).

For USSOCOM, the aids will be fairly simple, requiring no special development or production support. They will consist primarily of hard copy forms that address the specific types of information to be gathered and that provide for recording observations and responses to questions posed during interviews or in response to questionnaires.

Accomplish Data Collection: The data collection effort begins with coordination of the data collection schedule and itinerary with the organizations and units to be visited. After a schedule has been established, the data collection effort generally begins with a briefing of key managers within the user organizations. The briefing outlines the overall goal of the effort (establishment of a set of validated intelligence 
support requirements); the scope of the effort; the schedule; and the technical approach. It confirms methods, goals, and plans, and ensures that key managers are aware of the effort and committed to providing required coordination and support.

The techniques used for data collection involve well-established methodologies for performing requirements analysis. The methodology selected will usually drive the specific data collection requirements. Most commonly used methodologies include the DeMarco system (widely used in the intelligence community), and the Distributed Systems Analysis Methodology (DSAM), developed by Betac Corporation and used to support both intelligence and operations environments (currently used to support the Theater Intelligence Architecture Program (TIAP)).

During the interview process, data is collected and recorded on interview data collection sheets. Magnetic recording media may also be used in some instances when real-time recording using manual techniques is not practical.

Observation is as the term implies--observing actual performance of tasks and activities to determine what information is used and required, its source, format, classification, periodicity, etc. The results are recorded on forms. Exercises are an excellent forum for the observation technique.

Document research includes the full spectrum of hard- and softcopy documentation. It includes technical libraries, operations plans, policy and procedures documents (standard operating procedures), technical documentation (particularly documents directly related to intelligence products), organizational charts, and other documentation 
available and beneficial to the requirements determination process. Information taken from documented sources may be recorded on data collection forms or copied (within the constraints imposed by classification).

Questionnaires are similar to data collection sheets used during interviews; however, they are usually provided to targeted individuals or organizations and are completed without a data collection person directly involved. Questionnaires are commonly used when it is impractical to visit all locations involved in the data collection effort, or when it is impractical to personally interview all people who may be able to provide data beneficial to the analysis process.

Perform Data Correlation and Reduction: Data collection efforts of the magnitude required to determinate and document the USSOCOM intelligence support requirements demand involvement by several data collectors working simultaneously with different organizations. To effectively use the information collected during the subsequent analysis task, the data must be organized, correlated, and reduced to eliminate redundant and low-value data. This usually manual process involves separating and correlating data according to a functional scheme. After the correlation process is completed, the data is reviewed and evaluated. Redundant data is purged and lowvalue data is identified and set aside.for possible future use. The resulting correlated, high-value data is organized topically and reproduced in as many copies as required to support the analysis task. It is not uncommon to bind the collected data (usually in loose leaf binders) and to maintain a "master" copy. The collected data is assessed to identify any obvious shortfalls or omissions. Additional data is then collected to correct any such deficiencies. 
b. Requirements Analysis: After data collection is complete, USSOCOM intelligence support requirements can be tentatively defined. The product of this task is a document that lists, describes, and justifies those requirements. The document is then reviewed within the command for comment, correction, and coordination. After a final set of command-validated requirements is developed, it is provided to those DOD agencies/organizations responsible for validating intelligence support requirements.

The requirements analysis effort depends heavily upon a structured methodology to ensure that all aspects of intelligence support requirements are addressed, including:

- Essential Elements of Information (EEI)

- Additional elements of information

- Timeliness criteria

- Media (messages, imagery, maps/charts, etc.)

- Most probable sources - INPUT

- Internal intelligence support activities - PROCESS

- Intelligence products generated - OUTPUT

- Support system requirements (Comms, IDHS, Imagery Exploitation)

- Operating Scenarios (in garrison, out of garrison exercises)

- Other

The final list will far exceed this representative listing. 
The most common methodology used to develop intelligence functional and system support requirements is the approach developed by Dr. Tom DeMarco. The DeMarco methodology uses a work breakdown structure to identify each activity supported by intelligence products and relies upon graphic depictions to reflect the sources, processes, and "sinks" for each item of information. It is most useful for analyzing complex C3I environments and is especially beneficial in identifying gaps and deficiencies in intelligence support capabilities. A second similar methodology is Betac's Distributed Systems Analysis Methodology (DSAM). DSAM is also widely used in the Air Force ( $\mathrm{TAC}, \mathrm{MAC}$, and $\mathrm{SAC}$ ) and is used to support the Theater Intelligence Architecture Program at USCENTCOM, USSOCOM, USLANTCOM, SAC, MAC, and USSPACECOM.

Both methodologies employ similar techniques and produce similar products. The DSAM requires more automation than DeMarco and provides a greater variety of reports.

The first step in the analysis process is to select the methodology. The next step is to populate the associated database using information collected during the data collection effort. After sufficient data is incorporated into the database (manual or automated), processes for providing intelligence support can be identified, the source of supporting information defined, and the users of intelligence products identified. The analysis can then assess the current capabilities and identify deficiencies in terms of:

- Data availability

- Procedural deficiencies

- Reporting capability

- System deficiencies 
- Operational problems

- Interoperability issues

- Validity of requirements (assumes some requirements have already been established)

- Others (USSOCOM specific)

This process will result in a comprehensive listing of the intelligence support essential to the successful accomplishment of the USSOCOM mission, including the following requirements:

- Data elements

- Timeliness and periodicity

- Reliability and validity

- Database

- Interoperability

- Intelligence communications

- Reports/Products

- Distribution and dissemination

- Intelligence Data Handling System (IDHS)

- Intelligence Communications

- Other Intelligence support

The intelligence support requirements can then be defined and described in formal draft documentation. Format is usually dictated by the agency or organization responsible for requirement validation (often DIA). This process must consider data requirements, interface control, functional descriptions, system sizing and timing, and database specifications. 
c. Requirements Verification: The draft documentation describing USSOCOM intelligence support requirements must then be reviewed and verified by the various organizations and users of intelligence. Since these are many and diverse, the preferred technique is to produce multiple copies of the document(s) and to provide them, along with a schedule for completion of the review, to each of the organizations involved. After the comments of the users have been reviewed and corrections made to the draft documentation, an intelligence requirements review and validation conference is conducted for final validation prior to submission of the requirements to external agencies (such as DIA). The panel, a select (small) group of personnel qualified to verify the adequacy and correctness of the requirements, performs a final review.

d. Final Documentation Production: Following completion of the review and verification process by the using organizations, the intelligence requirements can be corrected, modified, or expanded accordingly. Any conflicting instructions and inconsistencies can be identified, negotiated, and resolved. A final document that sets forth the SOCOM intelligence support requirements in the format prescribed by the command or other validating agency can then be produced and distributed to the several using organizations and/or to the agency/organization responsible for requirements validation.

e. Intelligence Support Requirements Validation: If USSOCOM has the authority to validate its own requirements, this will have been completed. If not, the requirements will have to be validated by some external organization or agency. Often, the Defense Intelligence Agency or the National Security Agency has that responsibility. As a part of the validation process, the validated requirements are often incorporated into the GDIP, TIARA, and other intelligence support program areas. Some 
negotiation may be required to settle upon a final validated set of intelligence support requirements. USSOCOM J2 must take the lead in working with external agencies in achieving final validated requirements. 


\section{TITLE: INTELLIGENCE COLLECTION MANAGEMENT}

2. PURPOSE: To define USSOCOM's interim collection management requirements and to recommend courses of action to satisfy those requirements.

3. OVERVIEW: An effective collection management system is the means by which USCINCSOC tasks national- and theater-level collection assets to satisfy USSOCOM intelligence requirements. Intelligence collection management is the mechanism that provides special operations forces (SOF) with detailed intelligence to support mission planning and execution.

a. Background: The mission of USSOCOM is diverse and complex. Often planning and execution of SOF operations is severely time-constrained. In the "best case," sufficient transient priority accompanies the tasking (NCA-directed); only the channels to translate and implement that priority are needed for rapid response. In the "worst case" (preplanned theater targets, LIC), the availability of digitized DMA data and intelligence for the Third World is a function of priority, which has been historically low. Moreover, there are several inherent challenges to USSOCOM collection management efforts.

- Global responsibilities deny direct control of theater collection assets.

- Preplanned support of SOF missions must compete within theater collection priorities. Non-specific planning or execution needs (LIC, others) suffer low relative priority with collectors (and producers).

- Potential for NCA direction requires extraordinary reactions by collectors, disseminators, and users. 
These difficult challenges are the natural result of the diversity of capability and responsibility invested in USSOCOM. These "facts-of-life" require multiple, wellreasoned, and innovative approaches to collection management.

b. Baseline: Unlike other unified combatant commands, USSOCOM's collection manager cannot task "his" collection assets. USSOCOM has no "real estate" and few organic collection assets. USCINCSOC must rely almost solely on support from both national- and theater-level assets to collect intelligence. The only collection assets under direct USSOCOM control are assigned aircraft, teams, and possibly unattended sensors which would be employed immediately prior to or during the execution of a mission. This limited, real-time capability cannot be expected to generate a fraction of the total intelligence required for planning special operations missions.

HQ USSOCOM collection management functions reside in the Intelligence Directorate (J2). The Targeting and Collection Management Branch in the Plans, Operations, and Readiness Division of the J2 performs as the USSOCOM collection management office (CMO). The CMO interfaces with national intelligence agencies and coordinates collection issues with the U\&S commands, Services, DOD agencies, and SOC components.

The 1st SOCOM, USSOCOM's Army component, has a G2 Directorate responsible for collection management functions. The Collection Management and Dissemination Branch of the Plans, Production, and Dissemination Division performs the following duties:

- Coordinates the collection of information.

- Submits requests for aerial reconnaissance. 
- Responds to requests for detailed intelligence information from major subordinate units (MSU).

- Serves as the interface between MSUs and NSA on SIGINT matters.

- Serves as the 1st SOCOM representative on SIGINT at NSA.

- Provides SIGINT assistance to MSUs.

USSOCOM's Air Force component, 23rd Air Force, has a Deputy Chief of Staff/Intelligence Directorate (DCS/I) which provides peacetime intelligence support to the 23rd AF mission. An explicit collection management office or function is not identified. Further, its contingency role and wartime relationship to SOF units and the unified commands is unclear.

USSOCOM has not been assigned Navy SOF and consequently has no Navy component collection management office. The Navy Special Warfare Command is assigned; Navy operational units are not. It is not clear how USSOCOM will collect intelligence from or disseminate intelligence to deployed SEAL units.

\section{CONCEPT: USSOCOM's intelligence collection management system must} accommodate the specific needs of a wide variety of assigned forces, the diversity of assigned missions, and two fundamental modes of employment (supported/supporting). The system must be responsive, detailed, and accurate. It must accommodate circumstances in which the highest national priority and urgency may dictate direct and immediate access to most current, best available raw intelligence. At the other extreme, it must encompass in-depth, long-range predictive military, political, socio-economic studies in support of LIC and PsyOp missions. The Collection Management Office must control the priority and allocation of collection efforts across the spectrum of 
requirements. The command $\mathrm{CMO}$ must have both a means of establishing relative priorities within the command (priorities of need and urgency) and also the means to establish and exercise command priorities for national- and other level collection.

Control must be exercised at the highest level within the command's infrastructure because establishment of relative intra-command priorities is complicated by the inherent "jointness" of assigned missions. As an example, the AFSOC might well consider deeppenetration, relocatable threat targeting intelligence as its top priority for collection emphasis. The ARSOC might be satisfied with available intelligence for deep penetration ground operations and place its top priority on Central American insurgency even though AFSOC deep penetration survivability is essential to ARSOC missions. This dichotomy, while improbable, nonetheless illustrates the clear need for the joint command, not its components, to establish collection priorities.

A further complication for USSOCOM CMO is the relationship between USSOCOM, the SOCs, and theater commands. Given that the SOCs enjoy full support within the theater collection priorities, USSOCOM should be adequately served in either a supported or supporting role. If theater support of SOC requirements suffers through competition with other theater priorities, then USSOCOM must have the clout to influence the collection priorities within a theater to satisfy SOF requirements. Unfortunately, USCINCSOC's influence as a supporting commander may be inadequate since the establishment of collection priorities will remain the theater commander's prerogative. Conversely, as a potential supported command, USSOCOM has legitimate requirements to influence theater collection priorities. These requirements are somewhat tenuous due to the legislation's poor definition of the specific missions and objectives assigned to USSOCOM as a supported command. Thus, those missions in 
which USCINCSOC could exert legitimate influence on collection priority are not well defined; those which are well defined (preplanned theater targets) do not belong to USCINCSOC. In summary, USSOCOM has little effective leverage in influencing improved-theater collection for SOF; what little it has will derive from credibility of the SOCs and capability of SOF forces to contribute to successful execution of theater war strategies.

These inherent constraints at theater level should not alter USSOCOM's ability to advocate and effectively influence SOF collection priorities at the national level. The command, its Washington Office, and the $\mathrm{ASD}(\mathrm{SO} / \mathrm{LIC})$ are, by definition, strong advocates for the mission and intelligence support of SOF. With this in mind, it is at the national level that USSOCOM must address SOF priorities and SOF-peculiar collection needs (priority for LIC, PsyOp, and specific collection for SOF supported/supporting employment).

National-level collection management for USSOCOM for both long-lead and shortfuse environments now resides in the DIA. The likelihood of multiple crises involving USSOCOM and other U\&S Commands may strain and complicate the effectiveness of the DIA/NMIC/CCF collection management system. Priorities must therefore be clearly established on both an intra-USSOCOM and inter-U\&S Command basis as well. Further, collection management for USSOCOM at the national level must be evaluated in terms of knowledge of and access to non-governmental information sources such as universities and think tanks. These sources are exceptionally valuable in LIC or long lead-time environments when time-intensive and personnel-intensive detailed analyses can be conducted. The USSOCOM intelligence architecture must include procedures for accessing those non-governmental sources and the personnel who conduct detailed 
analyses (socio-economic, political, et al) although this appears to go beyond a collection management purview. These information sources are not likely to be accessible on a timely basis to support short-fuse situations involving collection management of national assets.

5. APPROACH: A first step in establishing USSOCOM's collection management program is definition of a command and component infrastructure used to develop requirements and priorities for intelligence collection. The necessity to identify CMOs or collection managers at each level is fundamental, but not necessarily straightforward given the "patchwork" nature of forces assigned to USSOCOM. The process by which components and SOCs develop requirements for collection, and the relative priority of those requirements, must also be analyzed for compatibility with command priorities.

Field interviews, questionnaires, and document studies can be used to determine how well existing collection management structure can satisfy USSOCOM's intelligence needs in peacetime, transitional peace-to-war, and wartime scenarios. Changes to or additional organizations, personnel, communications, equipment, procedures, and/or systems may be required.

The following general questions require specific answers:

- Which USSOCOM and non-USSOCOM organizations have collection management responsibilities for USSOCOM?

- Who (by name or billet) is responsible for collection management at each organization?

- How are collection requirements initiated, processed, and prioritized by USSOCOM components and SOCs?

- Which communications links are used or available for use by responsible collection managers? Are these links dedicated? 
- Does available communications equipment support format requirements? Does it present facsimile or text in easily readable format?

After answering these and other questions, the command can focus on problem areas and shortfalls. For example, Requests for Information (RFI), based on anticipated intelligence requirements, can be postulated and tracked through the collection management structure from the requestor up to, but not including, national collection management offices. Shortfalls in the peacetime collection management structure can then be identified, analyzed and corrected. Personnel may require new or updated training or equipment. Oganizational structures may require change. Communications links may have to be dedicated or procedures altered. For example, USCINCSOC may require flash override priority on certain circuits used by USSOCOM.

6. FEASIBILITY: Available collection management baseline information limits a thorough study without additional data collection and analysis; it is clear there are gaps in the component infrastructure inherited by USSOCOM--Navy SEAL units are not included. The poorly defined SOC/theater/USSOCOM relationship appears to effectively constrain USSOCOM prerogatives and influence. Lastly, as previously indicated, USSOCOM must direct considerable attention to addressing command needs at the national level.

An intensive study of USSOCOM collection management is technically and analytically feasible. The TIAP process will accomplish this task in the long term. In the short term, the command should focus its efforts on SOF advocacy at the national level and avenues for support of SOC needs within their theater collection infrastructure. 
7. RECOMMENDATIONS: To improve intelligence collection management, USSOCOM should:

a. Identify the organizations responsible for collection management within USSOCOM, U\&S Commands, and national-level agencies. Ensure that key personnel at each level are aware of USSOCOM's intelligence needs and roles in advocating for special operations intelligence collection.

b. Identify current shortfalls/gaps and determine courses of action to correct shortfalls.

c. Develop command collection priorities in conjunction with component/SOC CMOs.

d. Identify the communications links, modes, and procedures available to collection managers responsible for USSOCOM needs. This will allow USCINCSOC to evaluate communication connectivity and responsiveness in satisfying RFIs and tasking collection assets.

e. Consider early addition of one or more intelligence billets to the USSOCOM Washington office to advocate SOF interests at the national level.

f. Develop a cadre of personnel with broad experience in national and theater collection management. Study the JTENS (Joint-Service Tactical Exploitation of 
National Systems) and other sources of information on national and theater collection systems. Thoroughly understand the process by which RFIs are initiated, processed, validated, and satisfied.

g. Identify, document, and process USSOCOM-specific collection requirements.

h. Conduct an intelligence capabilities exercise to stress collection and dissemination systems and determine areas requiring improvement. 


\section{TITLE: INTELLIGENCE SUPPORT TO SPECIAL OPERATIONS TARGETING}

2. PURPOSE: To recommend the scope of USSOCOM's involvement in and support of the SOF targeting process and to define an approach for USSOCOM intelligence support to targeting.

3. OVERVIEW: Support to Special Operations targeting involves target selection, analysis, validation, prioritization, deconfliction, and postmission assessment. It is particularly important because USSOCOM has a global mission--non-theater-specific, but with information requirements more exacting than for the execution of any theater war plan. Additionally, USSOCOM must prepare to conduct selected special operations in peace or war, as directed by the NCA, concurrent with force organization, training, and planning to support theater requirements. Intelligence support to targeting is further complicated by the spectrum of conflict environments in which SOF may be employed--from the very tight focus of JSOC; to support of theater warfare; to national-level, top-down directed crisis response.

a. Background: SOF targeting support is traditionally characterized by joint Service employment as compared to single Service operations. It entails two distinct phases--the ability to get to and from the area of operations (AO) and the ability to successfully conduct the mission within the AO. These requirements effectively multiply the effort required to select, analyze, validate, prioritize, and deconflict SOF targets. Each valid target must be examined from at least three broad perspectives:

(1) Ability to insert a team, undetected, into a precise location within the target $\mathrm{AO}$. 
(2) Ability for the team to operate against the target(s) in the $\mathrm{AO}$, undetected, for periods ranging from hours to weeks.

(3) Ability to resupply and to extract the team, undetected in some cases, from locations within the AO.

During each step of this complex targeting process, intelligence and planning requirements are escalated because SOF operate in hostile controlled areas. This means deception must be an element in the SOF targeting process. Additionally, deconfliction involves not only the normal ingress/egress routes, but also establishment of a "sterilized" attack zone around the AO for the duration of operations.

The SOF considerations are in addition to normal targeting procedures which include research on target identification, development, weaponeering, and selection. Selected targets must be prioritized. The whole process must analyze these factors:

- Identification: What are the recognition signatures the SOF team needs to find the target?

- Criticality: How important is the target is to enemy operations; what does its loss cost them?

- Accessibility: Can the SOF team infiltrate (air, sea, land) to attack the target?

- Vulnerability: How much of the target must be destroyed to achieve the objective?

- Weaponeering: What are the effects of available allied and Warsaw Pact munitions on the target? What are the collateral damage impacts? Should SOF teams-steal local explosives rather than carry them?

- Recoverability: How much time is required for the enemy to repair or to replace the target (other targets may be vulnerable during down time)? 
As with any difficult, man-hour-intensive task, technology may improve timeliness, quality, and responsiveness to SOF mission planning targeting support. USSOCOM urgently needs to investigate systems which may offer improvements in quality or responsiveness, and effectively interface with existing and programmed theater mission planning and intelligence systems.

b. Baseline: Preplanned SOF targets are the responsibility of theater commanders. Potential preplanned targets are currently "scrubbed" by SOF theater component staffs (SOCs and units) in an iterative process to assure that ingress/egress, normally by air, is feasible, and that ground/sea team operation (whether direct action, surveillance, or other) is also feasible. This process requires detailed mission planning and threat analysis, again as an iterative procedure, to determine the best route, timing, altitudes, insert locations, etc., to avoid detection. It is a difficult task, often requiring compromises between the most efficient flight routes and the operational needs of the team. Hours of darkness, projected local weather, terrain masking, availability of drop/landing zones, threat detection and avoidance, and many other factors are integral to the process. The quality and accuracy of intelligence support are critical to determining feasibility, since some of the most important SOF missions could occur before declared hostilities.

When the potential target is determined to be feasible, that judgment passes through the unified command structure for validation. Once validated, more intensive mission and deconfliction planning produces a target folder, which requires periodic updating to reflect changes in theater strategy or friendly and enemy capabilities. 
While there is currently no standard procedure for development of short-notice or crisis targets, the same iterative steps must be executed. This compressed process may be degraded by inability to coordinate between air and ground planners due to concurrency in development of their separate but interdependent plans. Responsiveness and quality of intelligence support to crisis targeting may be similarly constrained by the time and communications channels available to coordinate and plan.

4. CONCEPT: Effective intelligence support to SOF targeting is essential. Developing effective intelligence support is both an opportunity and a challenge.

The theater commander is responsible for selecting, validating, and prioritizing his war plan targets; SOF targets are a small but very important part of the theater target list. Nonetheless, it is unlikely that the SOCs will ever acquire sufficient intelligence personnel to develop and maintain detailed target materials for every potential theater target. The establishment of USSOCOM provides, for the first time, a pool of dedicated SOF intelligence expertise which may be allocated to provide intelligence support to theater SOF targeting. USSOCOM additionally may be expected to have access to resources not available to the SOCs to develop and acquire technology in order to speed and improve intelligence support to targeting.

USSOCOM support of the SOCs' targeting efforts offer several significant advantages to the command. It provides the USSOCOM staff with detailed insight into the operational, geographic, and threat environments that its assigned forces must be prepared to encounter. It provides opportunities to ensure interoperability and/or standardization of SOF-peculiar intelligence procedures, products, and communications. It further provides hands-on targeting training and experience to USSOCOM intelligence 
personnel in preparing for NCA-directed missions in which USSOCOM is the supported CINC. (It alternatively prepares them for effective augmentation of SOCs when USSOCOM is supporting.)

A major intangible benefit of USSOCOM intelligence support of theater SOF targeting is the clear signal it offers theater combatant commands that USSOCOM can and will support them without encroaching upon their assigned responsibilities.

Another critical aspect of this support is the overriding importance of ensuring that joint SOF are prepared to execute missions against validated, preplanned theater targets. This preparation is a fundamental, but often overlooked element in the revitalization of SOF. As joint SOF force structure and capabilities grow and improve, long-standing deficiencies in target planning may become the Achilles heel of successful employment strategy. SOF force structure is derived from requirements based on the number, type, and location of valid targets assigned by the theater. Having acquired force structure based on valid targets, unified combatant commanders will properly expect that SOF will have completed detailed planning for execution of operations against their target folders.

There is no panacea for time-constrained crisis planning difficulties; however, those actions that contribute to more efficient preplanned target development will also contribute to crisis performance. They are:

- Development of appropriate skills, knowledge, and experience within a targeting cadre.

- Development of disciplines by continuous interface with theater planners and national-level intelligence producers. 
- Identification and acquisition of systems to speed and improve the quality of intelligence support to the mission planning process.

- Organization and communications which facilitate continuous coordination during concurrent operations/intelligence target planning efforts. Establishment of an intelligence coordination center (ICC) may be an important element of USSOCOM crisis response.

5. APPROACH: USSOCOM requires detailed knowledge of theater targeting procedures, processes, and needs. Discussions with SOC and theater-based unit intelligence staffs should provide preliminary assessments of the type and amount of assistance required from USSOCOM to eliminate backlogs of target studies and updates.

Given a preliminary status of theater needs, USSOCOM J-2 should begin initial planning to focus its efforts and to organize to provide needed support. Certain assumptions will sharpen that focus:

a. Validated theater targets are the basis of SOF force structure and capability requirements. Intelligence support of the targeting process is critical. USSOCOM has intelligence resources available to assist theater SOCs.

b. USSOCOM should not be responsible for the production and maintenance of masses of intelligence, but will rely on existing agencies for support. Emphasis will be on validated and prioritized requirements, liaison, and assistance, not on production. Validation and priority of theater preplanned targets are theater command responsibilities.

c. Special operations target packages cannot be produced and updated for every conceptual target worldwide. A quick-reaction technique needs to be developed to prepare target packages. This must include automated mission planning systems. 
d. USSOCOM J-2 should take the lead in advocating RD\&A activities on behalf of USSOCOM and the theater SOCs. Resources available to USSOCOM are unlikely to be matched in any theater for dedication to SOF targeting.

USSOCOM's role in the targeting process is leadership and support of initiatives to streamline, integrate, and improve responsiveness of an inherently joint and potentially cumbersome process. Accordingly, USSOCOM should:

a. Examine the targeting process, products, and available resources within each theater.

b. Analyze shortfalls in personnel, procedures, and processing which USSOCOM, by virtue of assigned responsibilities and available resources, must redress.

c. Determine the scope of assistance needed by the theaters (manpower, technology, priority). The goal is usable target folders for validated targets.

d. Develop a plan to provide needed assistance to the SOCs. This may require internal realignment of USSOCOM intelligence and operations staff resources.

e. Develop procedures to review_available and potential technology to identify systems capable of improving quality and responsiveness of intelligence support to SOF targeting. Include procedures for validation of SOF units (assigned or non-assigned) requirements and J-2 advocacy within MFP-11 (USSOCOM or Service). 
f. Analyze "ideal" procedures and processes for preplanned targeting and exercise them against time-constrained crisis scenarios (factual or notional). Determine critical nodes and choke points in the crisis targeting process. Develop crisis response guidelines to ensure optimal coordination of concurrent operational planning and intelligence support.

6. FEASIBILITY: The USSOCOM role in intelligence support to special operations targeting is established by the command's responsibilities as a supporting command, its needs as a supported command, its responsibilities to validate requirements, and its advocacy of joint SOF in the PPBS.

Determining the scope and method of providing that support lends itself to intensive review of current status and an examination of support USSOCOM can provide to correct identified shortfalls. This analysis will provide USSOCOM opportunities to assist theater targeting while contributing to its readiness as a provider of trained forces. It will provide useful guidelines for developing those crisis response procedures expected to be required for NCA-directed missions.

This analysis is technically and analytically feasible. It requires support and cooperation from the theater SOCs to be effective, but yields significant mutual benefits both to the theaters and to USSOCOM. The most difficult aspect of this effort may be achievement of standardized approaches from the various theaters.

7. RECOMMENDATIONS: Intelligence support to special operations targeting provides an extraordinarily important opportunity for mutually beneficial USSOCOM support of the theater combatant commands. The viability of support provided is essential to 
initial and future USSOCOM credibility with the theaters. Theater expectations will be predictably high; USSOCOM should be cautious to limit support commitments to achievable levels. A thoroughly planned, well-prepared effort is required to ensure that the support provided goes beyond provision of temporary manpower augmentation. This issue offers USSOCOM, in conjunction with the theater SOCs, the opportunity to institutionalize the formal and informal theater relationships. The organizational interfaces of the intelligence role in the requirements process will help define infrastructure and guidelines for USSOCOM crisis response. USSOCOM J-2 should:

a. Develop a targeting cadre with SOF skills and experience.

b. Initiate preliminary dialogue with theater SOCs and national agencies; determine processes, status, and theater-peculiar shortfalls in intelligence support of SOF targeting.

c. Analyze theater needs, determine USSOCOM support required, and initiate those actions necessary within USSOCOM (organization, personnel, skills, technology, systems) to provide theater support. Inadequate preparation to assist may result in nonproductive assistance and missed opportunities for productive, long-term relationships.

d. Develop a plan of action with USSOCOM J-3 and the SOCs to provide assistance. J-3 responsibilities for detailed mission planning in support of targeting are at least equal to J-2's; the iterative nature of the tasks requires concerted effort. Concurrently, USSOCOM should initiate procedures for identification and validation of 
theater needs for intelligence support of SOF targeting (assistance, personnel, SOFpeculiar equipment). The cadre should identify automated mission planning systems and national database update requirements.

e. Consider the intelligence annex of the Joint Master Plan as an appropriate and timely means for coordinating the plan of action internally, within the command, as well as externally.

f. Analyze crisis response support as a time-constrained extension of the preplanned targeting process. Examine critical nodes, responsiveness, coordination, planning concurrency, and the effective application of priorities attendant to crisis. Identify systems which enhance the quality and timeliness of crisis planning. Develop both long- and short-term organizational and procurement plans to support crisis response. (JSOC experience will be invaluable in this effort, for both equipment and procedures.) Consider an Intelligence Coordination Center (ICC).

g. Task the cadre to include strategic and tactical deception in the SOF targeting process.

h. Develop internal procedures to identify emerging technology, to exploit it for targeting and mission planning, and to succeed in getting it funded and procured.

i. Develop procedures to exercise mission planning and targeting capabilities in crisis response conditions, real or simulated. 


\section{TITLE: JOINT MISSION AREA ANALYSIS (JMAA)}

2. PURPOSE: To review USSOCOM legislation and outline a requirements approach to Joint Mission Area Analysis (JMAA) in support of Special Operations and Low Intensity Conflict.

3. OVERVIEW: Mission Area Analysis (MAA) dates back to the Congressional Budget Impoundment Control Act of 1974, but its primary focus--identifying mission needs and requirements for development and acquisition--goes back to the origins of the Planning, Programming, and Budgeting System (PPBS) of former SECDEF McNamara. MAA is a key aspect of the process by which requirements are identified, justified, reviewed, validated, and prioritized for funding.

a. Background: The legislation which formed the new command with its exceptionally broad mission specifically charges USCINCSOC with the authority to remedy perceived problems in readiness and capability. It is not surprising that DOD took exception to these Congressional perceptions. When compared to the legislation, including the proposed Hutto Amendment (pending), the JCS Statement of Missions and Functions (JCSM 71-87) indicates a marked difference in interpretation between the Congress and the DOD. Clearly, USSOCOM was formed in an adversarial environment and many issues remain unresolved. - This situation will continue to challenge the command as it struggles to develop and will have an impact on all command functions, including JMAA. 
The legislation is specific on many points. It forms a new combatant command under a four-star officer. It establishes a new Assistant Secretary of Defense for Special Operations and Low Intensity Conflict (ASD(SO/LIC)). It places all CONUS active and reserve forces listed in the Joint Strategic Capabilities Plan (JSCP), Annex E, into USSOCOM. Although the theater CINCs retain operational command of SOF in their theaters, USCINCSOC may be a supported CINC when so directed by the President or SECDEF. Importantly, the legislation specifically charges USCINCSOC with the authority and responsibility to:

- Develop strategy, doctrine, and tactics;

- Train assigned forces;

- Conduct SOF courses for both officers and enlisted personnel;

- Ensure combat readiness;

- Establish priorities for requirements;

- Validate requirements;

- Develop and acquire SOF equipment, materiel, supplies, and services;

- Ensure interoperability of equipment and forces;

- Formulate and task requirements for intelligence support; and

- Monitor promotions, assignments, retention, training, and professional military education for SOF officers.

The legislation reiterates USCINCSOC's responsibility to monitor combat readiness of SOF to carry out assigned missions in other unified commands. It establishes MFP 11 and commensurate budget authority. It includes forces of the Joint Special Operations Command. It forbids special activities without proper authority and notification of Congress. Further, it defines ten special operations activities: 
- Direct action

- Strategic reconnaissance

- Unconventional warfare

- Foreign internal defense

- Civil affairs

- Psychological operations

- Counterterrorism

- Humanitarian assistance

- Theater search and rescue

- Other activities specified by the President or the SECDEF.

The legislation also requires the President to report to the Congress by October 16, 1987, on the capabilities of the United States to conduct special operations and low intensity conflict. The report must include deficiencies, corrective actions, principal LIC threats, and actions to implement the law. A summary of USSOCOM's mission, capabilities, and progress as a command, which represents extensive Mission Area Analysis, should be the focus of the report now being drafted by the NSC and OSD.

In addition to the legislation, there is a Senate Armed Services Committee requirement for USSOCOM to report, by January 5, 1988, on the long-term desirability of moving HQ USSOCOM from MacDill AFB, Florida, to Washington, D.C. There is also an amendment to the FY88 Authorization Bill pending (the so-called Hutto Amendment) which will further clarify the budget authority of USCINCSOC. Significantly, it provides USSOCOM with up to 120 civilian positions to support engineering, $R \& D$, natural sciences, medicine, communications, electronics, aviation, program management, contracting, warehousing, depot operations, testing, procurement, finance, budget, and 
automation systems. It establishes the authority of the $\mathrm{ASD}(\mathrm{SO} / \mathrm{LIC})$ as "the principal advisor" to the SECDEF on special operations and low intensity conflict matters and designates $\mathrm{ASD}(\mathrm{SO} / \mathrm{LIC})$ as the principal special operations and low intensity conflict official within the senior management of the Department of Defense.

The Congressional language is notably more direct and far-reaching than the May 29, 1987, JCS Missions and Functions Statement of USSOCOM which stipulates only seven functions for USCINCSOC:

- Provide OPSEC for SOF

- Train assigned forces

- Advise SECDEF and JCS on SOF capabilities and employment

- Develop inputs on SOF for the Joint Strategic Planning System

- Participate in the PPBS with an Integrated Priority List (IPL) to advise and to consult SECDEF, ASD(SO/LIC), and the Chairman, JCS

- Monitor promotions, assignments, retention, training, and professional military education of SOF

- Develop required command agreements, memoranda of understanding, and letters of agreement with commands, agencies, and working groups.

b. Baseline: OSD has formal procedures governing the participation of the U\&S Commands in the PPBS process; however, the CINCs' role in the requirements process is less clear. There is no defined joint mission area analysis or requirement for it. The Army is now the only Service maintaining a formal mission area analysis procedure through its Training and Doctrine Command (TRADOC). The Air Force no longer has a formal MAA Program Office and MAA functions have been transferred to the Air Force's Plans and Programs/Resources Directorates. The Navy's MAA process more closely parallels the Air Force's than the Army's, but it is even less formal. A Navy 
operational directorate may both validate and fund a requirement. The OSD procedures include a Requirements Review Group (RRG) for validation of joint requirements. The CINCs may submit requirements to the Services, JCS, or the Defense Resources Board (DRB). The CINCs may also offer suggestions to SECDEF for the Defense Guidance. The CINCs identify requirements directly to the Services and prioritize them on Integrated Priority Lists (IPLs). These requirements are included in a budget annex, which identifies whether they were filled and provides accompanying rationale. The CINCs also participate as advisors to the DRB during the "Issues Cycle." USCINCSOC will chart new territory as he participates in this process with aggregated Service SOF programs within MFP 11 and with the SOF validation authority granted him by law. This will not occur for the FYDP 89-93 adjustments.

4. CONCEPT: Since there is no existing standard for mission area analysis, USSOCOM must establish its own formal mechanism and approach. A thorough analysis and evaluation of the ten SOF activities identified in the legislation will require extraordinary expertise in the SOF arena. Employing joint Service assets in a cohesive, fighting strategy or employing SOF tactics in direct action, UW, counterterrorism, foreign internal defense, or the other designated activities will generate requirements which have not yet been formally identified or documented. Many of these joint requirements, which will be the foundation of JMAA, have never been adequately addressed by the Services. Adequately addressing these issues from the joint SOF perspective will tax the resources and expertise now assigned to the command. As with other crucial challenges facing the command, additional expertise and assistance must be solicited from outside agencies. 
5. APPROACH: The first place to start is with the Services. USSOCOM inherits the Service efforts to date in the areas of SOF requirements, planning annexes, and programs. This includes aspects of JMAA such as requirements validation, programming, budgeting, and support. Those items in the pipeline become USSOCOM programs, with which USSOCOM must rapidly become familiar. Those requirements that have been validated within the Services but have been neither programmed nor funded must be reviewed in light of USSOCOM's joint perspective.

Next, USSOCOM must examine the theater CINC requirements the Service programs support. Again, the joint perspective of USSOCOM will likely create a different set of priorities. USSOCOM will have to work very closely with the other CINCs to resolve differences revealed by JMAA.

There are several ways to attack the problem. The simplest is to break down USSOCOM's legislated mission areas, counterterrorism, unconventional warfare, and low intensity conflict, according to the known requirements.

Importantly, the theater CINCs, at the direction of DOD and the Congress, have reviewed and revalidated their SOF requirements--target-by-target, team-by-team, sortie-by-sortie--at least three times in the past four years. This process itself may represent a "quick and dirty" approach to JMAA in the short term. After much scrutiny, SOF unconventional warfare requirements have been validated by DOD and certified to Congress. The process has clearly shown that assigned and available SOF assets are not sufficient to satisfy the requirements identified. The shortfalls must be analyzed in a joint context. Moreover, USSOCOM must go well beyond the efforts to 
date because the USCINCSOC charter is broader. This requirement should quickly surface in the USSOCOM Joint Master Plan since its perspective will be radically different from combined Service Master Plans of the past.

Aside from the lack of a joint perspective, previous efforts in MAA, requirements analysis, and master planning did not begin to address the areas of foreign internal defense, civil affairs, psychological operations, humanitarian assistance, and SOF theater rescue, which are now primary USSOCOM concerns. While a theater CINC might direct forces to satisfy fleeting needs, no Service has ever programmed resources to satisfy these largely "unknown" requirements. Many of these mission areas require much more than a joint perspective. They require combined, interagency reviews and, possibly, allied cooperation. These issues pose a significant challenge to USCINCSOC but are clearly integral to USSOCOM's broad responsibilities in both peace and war.

While combat mission requirements must take priority, the command's broad peacetime support responsibilities are equally challenging to the JMAA process. USSOCOM must monitor the promotions, assignments, and retention of SOF; develop strategy, doctrine, and tactics; and must monitor SOF combat readiness in other unified commands. All JMAA activities will require close cooperation and support from the theater SOCs. This close relationship must be established early and on both formal and informal terms.

Internally, the functional staff must attack JMAA agressively. The J-3 should be the lead agency in JMAA requirement definition. The associated requirements in the other J-staff agencies will be a direct result of operational needs. JMAA will be an iterative and, at times, painful process. The entire staff must fully appreciate the 
nature, scope, and urgency of the JMAA methodology. USSOCOM must be fluent, persuasive, and thorough in translating paper requirements into the force structure to fulfill its broad mission. A comprehensive JMAA effort will establish a framework to successfully compete for the resources necessary to achieve this important command objective.

6. FEASIBILITY: Further effort in the area of JMAA is essential. Whether it is termed MAA, requirements validation, or the resource programming process, USSOCOM must be totally involved. The legislation establishes the responsibility and authority; the competition for resources establishes the necessity.

7. RECOMMENDATIONS: USSOCOM will be blazing a new trail for a unified command, since current requirements review groups work at the Service level and go directly to the JCS. Other CINCs comment but do not control requirements resource programming. USCINCSOC will participate directly as soon as the command is prepared to take on the challenge. The following recommendations will help speed the process:

a. Obtain and review the theater CINC SOF requirements study conducted by the Services for the 1986 SOF Master Plan effort. This study looked at theater war plans by target, team, and sortie in terms of SOF infiltration, resupply, and exfiltration. It was a groundbreaking effort that will directly assist the review of unconventional warfare requirements. It will also provide good background for looking at CT, LIC, and indigenous support requirements. 
b. Get directly involved in the OSD and NSC effort to prepare the President's Report to Congress on Special Operations and Low Intensity Conflict threats, capabilities, deficiencies, and corrective actions. The report should go directly to the heart of USSOCOM mission and needs. Active participation by the command will provide perspective, continuity, and emphasis to subsequent USSOCOM efforts to validate requirements. Additionally, experienced JSAG or JSOIC staff members need to understand and, perhaps, influence the often opposing viewpoints in the Washington area. At some point, USSOCOM will have to choose its own way.

c. Examine the near-term and long-term (ten years hence) threats to the ten SO/LIC mission areas specified in the law. While this effort may not go further than similar analyses prepared for inclusion in the October 16, 1987, President's Report, there is a need for the command to validate that report and take the lead in defining the threat, identifying problems, and providing solutions.

d. Develop a baseline compendium of all active and reserve SOF units. Include resources, personnel status, programmed growth, promotion histories, professional military education profiles, and retention records. A baseline is essential to measuring success in the future. Developing the database will require close coordination with Services, SOCs, and components and will help to establish good working relationships at the commander and action officer levels. It will also provide a means to assess the health of these relationships.

e. Work with the Services through MFP 11 to ensure that programmed solutions for existing deficiencies are on track and will continue to progress smoothly. This process will help establish the relationships needed to build an effective mission 
requirements validation process, which should provide an initial evaluation of how much or how little is being done to remedy deficiencies already identified for USSOCOM components and theater SOCs.

f. Review USSOCOM mission areas by theater to determine the need for coordinating vehicles, between USSOCOM and other commands, which address SOF requirements validation, funding, and support. This should include both wartime and peacetime mission functions, requirements, personnel, training, strategy, doctrine, and tactics.

g. Use the data gathered from all of these activities to form the basis of the USSOCOM Joint SOF Master Plan and to guide development of the programming documents that will guide the FY90-94 POM process, the command's first formal entry into the full PPBS process. 


\section{TITLE: JOINT SOF MASTER PLAN}

2. PURPOSE: To recommend actions to guide development of a Joint SOF Master Plan.

3. OVERVIEW: USSOCOM requires a Master Plan to integrate Service and component assets. The USSOCOM Master Plan must consciously seek ways to free the process of Service parochialism. This paper recommends a methodology and approach for this Master Plan to allow the USSOCOM staff to rapidly begin work on the plan itself with immediate access to necessary background data on methodology, structures, and force planning data.

a. Background: The Services were directed to provide SOF Master Plans to OSD by a 1983 DEPSECDEF memo to the Service Secretaries and Chiefs. This directive was in addition to, but clearly related to, four tasks assigned the Services by the memo. The plans were signed and forwarded to OSD by the Service Secretaries in 1984. These Service Master Plans, updated in 1987, were suited to Service needs and were not balanced in terms of force structure, programs, doctrine, and understanding. The Navy, for instance, did not commit SEALS to a joint Service force; instead it kept them under naval fleet command.

The Army and Air Force plans were largely rendered invalid by the CSA/CSAF Memorandum of Agreement approved by the Chiefs on 17 May 1984. Initiative 17 of the 31 original "Joint Force Development" initiatives called for creation of a plan to transfer rotary wing support of SOF from the Air Force to the Army. The Initiative created controversy within Congress, OSD, the Special Operations Policy Advisory Group, and the Service staffs that disrupted their efforts to achieve an integrated plan 
for balanced, rational, and achievable improvements in joint special operations forces. Required Master Plan reviews and updates were consciously forsaken in view of the turbulence.

b. Baseline: Aside from the disruptive impact of $1-17$, the Service plans were conceived and approved as conceptual plans--as goals, not as programs. Execution of the individual plans, both in timing and budget support, was dictated by internal competition for resources within individual Service budgets. One of USSOCOM's primary goals must be to change this. During each of the PPBS cycles since approval of the plans in 1984, the Defense Resources Board has intervened to increase SOF funding above Service requests. While each Service supported the goals of its respective master plan (albeit with varying consistency), there was no effective effort to phase and to coordinate program changes across DOD special operations forces. In summary, while OSD, the Congress, and the Services have applied considerable energies and funding to the improvement of our national special operations posture, a strong, coherent, and credible effort to balance those expenditures has been lacking. In fact, the DEPSECDEF directive for priority and budget review has been virtually ignored in subsequent Service deliberations. The directed procedure for OSD comptroller and PDASD/ISA review of SOF program changes was never exercised.

4. CONCEPT: The goal of the Joint SOF Master Plan must be to achieve balanced improvement in assigned forces, both qualitatively and quantitatively. All factors leading to successful force employment must be addressed. There has been a misguided tendency in the past to equate growth in numbers with improved capability; to sacrifice opportunities for quality in a desire for finite quantities of dollars, troops, units, missions. Pressures to prolong that tendency will be particularly burdensome to 
USCINCSOC. The USSOCOM Master Plan provides an opportunity to control those pressures in a coherent, integrated roadmap for future joint special operations forces. The congressional action leading to the creation of USSOCOM dictates improvements in both quantity and quality, but demands quality. The ability of the command to credibly detail its purpose and goals lies in a comprehensive description of its current and programmed status and a plan for its future.

5. APPROACH: The Service Master Plans represent concerted efforts to describe what must be done to improve capabilities within each Service's peculiar constraints and priorities. What is lacking is an objective analysis of common goals and a campaign plan to re-orient and rephase disconnects in individual Service plans from the joint force perspective. As an example of a successful joint perspective, Air Force/Army iterations of forces required for infiltration/exfiltration/resupply have been linked by common, validated theater requirements. While the choice and mix of platforms to meet the requirements have been contentious (Initiative 17), the requirements themselves have been revalidated repeatedly and have served as a solid basis for required force structure projections. They have served as a rare common denominator for timing and sizing of joint force growth; they have been thoroughly scrutinized and remain virtually uncontested after Service, JCS, OSD, and Congressional reviews. The requirements study drove the three Service component master plans. It is important that USSOCOM's initial goals be well founded, joint in perspective, and credible (if not immediately achievable.) Importantly, the command must not rely too heavily on specific, but possibly transient, near-term requirements. These missions will fade away with time. USSOCOM must focus on the Service components and address SOF 
requirements and mission at the theater level. (EUCOM, PACOM, and SOUTHCOM have SOF assigned. EUCOM, PACOM, CENTCOM, LANTCOM and SOUTHCOM receive chopped forces). Theater SOCs are critical elements of this approach.

Collateral efforts are required in virtually all "support" functions: personnel, logistics, intelligence, communications, C2, doctrine, training. An objective, "stand-off" analysis of each Service's posture and procedures should identify those goals which are common to joint employment improvement as well as divergent potential problem areas. Interoperability and infrastructures, both within the mission area and also with conventional forces, must be important objectives of these analyses. Inherent reliability and redundancy needs must be carefully measured against unproductive and unaffordable duplication across Service lines. Dependent upon the final configuration of Major Force Program (MFP) 11, USSOCOM may even enjoy some flexibility to manipulate funds within the MFP to achieve balance across the total SOF program; it must be prepared to take advantage of this extraordinary opportunity.

Given that current Service Master Plans reflect Service positions and goals for the future, the analysis supporting the Joint Master Plan should reflect three broad purposes and objectives:

- Baseline: A description of current status of assigned forces, infrastructures, issues - baseline against which future performance will be measured.

- Program: A compilation of programmed change and an analysis of those programs which lead to imbalance of the joint force in phasing, in force structure size, or in content/purpose.

- Plan: A comparison of current and programmed elements assigned to USSOCOM against USSOCOM goals established by legislation, charter, doctrine, and milestones to achieve an orderly program which fulfills those goals. 
The first two objectives can be met by study of existing forces and current programs. These tasks involve compiling Service programs in a coherent format to portray current and programmed forces. Ideally this effort would highlight any inconsistencies in programmed changes of quantity, quality, location, or phasing. It would suggest modifications to Service programs to assist USSOCOM in achieving balance and integration of the joint force and provide the framework for establishment of priorities among programs. It will certainly root out those areas which USSOCOM should, but does not, "own." The effort should establish a mechanism to direct or to influence such areas.

The third objective establishes a short- and long-term roadmap for progress to achieve USSOCOM goals, the ultimate benefit of the Joint Master Plan. Whereas the first two objectives yield apparent disconnects or mismatches in existing Service plans, the third measures those plans against joint goals and objectives. In this respect, Joint Mission Area Analysis becomes a supporting analysis (an appendix primarily given to support of force structure) to the Master Plan. But the Master Plan should clearly encompass all avenues to achievement of USSOCOM goals, quality as well as quantity, tail as well as tooth. Accordingly, it should address all elements in the spectrum of joint readiness and evaluate them in terms of the three objectives (current status, programmed change, USSOCOM goals).

An excellent example of the analysis required for one element of the Joint Master Plan is personnel. Possibly the most contentious and certainly the most important factor in joint readiness. SOF personnel policies vary widely across the Service elements assigned to USSOCOM. Long-standing and often traditional Service personnel policies are extremely sensitive issues to the individual Services. These may in some 
instances be irrelevant, inadequate, or counterproductive to the mandated goals of USSOCOM. For example, from the most demanding personnel selection processes in the military (JSOC, SEALS, SF) to the minimum qualification criteria of number of flying hours in similar aircraft (23AF, SOLL), the Services utilize dramatically different standards of selection and qualification. These differences may well meet SOF mission requirements, but an objective, joint analysis may equally well reveal need for change. Additionally, the Cohen-Nunn Amendment legislates broad responsibilities to USSOCOM to ensure the quality of the joint personnel assigned.

An in-depth analysis of current Service personnel policies is a prerequisite to fulfillment of those responsibilities and will provide USSOCOM the best guarantee of stability and excellence for the long term. Evaluated against the USSOCOM missions and functions, this analysis will unquestionably highlight needed improvements in selection, training, education, and advancement for joint SOF personnel. Even if it should not, step one of the analysis, the baseline, will highlight needed changes in view of inherent USSOCOM responsibilities to establish the highest SOF experience level possible. Because the personnel systems of all Services react to the macro factors of budget, manpower ceilings, acquisition/retention rates, training costs and capabilities, attrition, promotion rates, etc., it is imperative that the USSOCOM establish its particular requirements early and firmly. The Joint SOF Master Plan provides an excellent vehicle to clearly establish the comprehensive personnel goals mandated as well as implied by legislation and required by approved missions and functions. 
The Joint SOF Master Plan should establish starting points or benchmarks, in each functional area, against which future progress may be evaluated. If executed comprehensively, it will undoubtedly expose gaps which have developed in the separate Service programs to revitalize their SOF. It will additionally present initiatives which may be vital to the earliest readiness of USSOCOM. As an example, an initial generic action to assign a formal DOD priority during establishment of the headquarters (Force Activity Designator I or II for a period of 18-24 months) would greatly assist efforts to consolidate, modify, or improve existing communications, facilities, and most, if not all, functional elements required to put the headquarters into operation. This action should gain approval quickly as it would have minimal impact on the Services, is clearly a closed-end, one-time requirement, and would serve as a highly visible measure of JCS and DOD support of USSOCOM. A similar generic initiative might be a request to the Services to conduct formal instruction on the individual processes each uses to build and support its Program Objective Memorandum. The process would provide mutual benefits for USSOCOM and the Services. On the one hand, Service personnel would be introduced to the challenges and imperatives of the new command; on the other, the command could quickly get a broad view of Service procedures.

The value of arraying and analyzing benchmark data for each major function of assigned Service components should not be limited to suggestions for short-term, limited actions to establish the command. This process inherently identifies long-term requirements made obvious by the benchmark program review. An excellent example of letting a requirement grow into a program is the USSOUTHCOM STOL aircraft. For years, there was a need for a rugged, small airlift aircraft to reach isolated locations, but the need was never expressed as a valid requirement. When the 1986 DRB reviewed the validated requirement, it directed procurement of ten aircraft. 
6. FEASIBILITY: For all the reasons listed, the Joint SOF Master Plan is pivotal in the solid establishment of USSOCOM and the fulfillment of its charter. It should provide a relatively early and widely available statement of basic doctrine for the command: It enjoys flexibility which accommodates not only the diversity of missions, forces, and responsibilities assigned, but also the unprecedented nature of the U.S. Special Operations Command. While much of the data required to initiate the baseline or benchmark phase of master plan construction is readily available, the effort required to format this data coherently will be significant and crucial to the credible execution of the plan. The baseline is, in effect, the basis of USSOCOM's effort to improve joint special operations forces. The Joint SOF Master Plan is the best vehicle by which to comprehensively address the many challenges facing the new command.

7. RECOMMENDATIONS: The inherent utility of the Joint SOF Master Plan as a means to establish USSOCOM goals and to identify the steps required to achieve them lies in the flexible format. The basic plan should establish and support broad mission responsibilities derived from the body of approved doctrine, guidance, theater requirements, and USSOCOM mission and functions. The specific actions necessary to fulfill those responsibilities may be defined in annexes to the basic plan and should in each case include target milestones for accomplishment. Suggested annexes are personnel, logistics, intelligence, C2, command relationships, force structure, communications, research and development, mobility, and readiness. (See Tab 1 for a suggested format.) One or more compartmented annexes may be required.

Analysis for each of the annexes requires collection of approved current baseline and program data from each of the Services. Evaluation of these data against criteria established in the basic plan may reveal economies of effort, redundancies, deficiencies, 
and initiatives which are legitimate USSOCOM interests and to which the command must address its efforts and influence. Again, using personnel as an example, the following checklist is appropriate:

a. Collect personnel data (selection, promotion, training, education, qualification requirements, experience levels) from all components for SOF-peculiar operational specialties.

b. In addition to SOF operations specialists, identify other support personnel possessing previous SOF training and experience (intelligence, logistics, plans, communications, etc.).

c. Identify apparent voids and deficiencies (e.g., exchange tours) in current and planned/programmed status.

d. Evaluate existing and programmed Service policies for adequacy against USSOCOM experience requirements.

e. Recommend avenues for change where required; identify those deficiencies that are amenable to correction by the Services as opposed to those where it is more prudent to carve out some degree of direct USSOCOM responsibility (e.g., nomination of theater SOC commanders, command recognition program, specialized but not necessarily formal training).

f. Define those actions necessary to achieve the goal. Suggest strategies and target milestones for achievement. 
The following general receommendations should apply to all annexes of the Joint SOF Master Plan, not just personnel.

a. Isolate component redundancies and replace them with economy of effort.

b. Review compartmented programs and other areas for consideration of annexes.

c. State validated and peculiar requirements as goals.

d. Emphasize the value of readiness and growth supported by balanced, joint analysis of common goals and plans.

e. Write short- and long-term roadmaps for balanced program growth.

f. Baseline current programs and existing forces to measure future progress.

g. Do not sacrifice quality for quantity. 
TAB 1

SUGGESTED FORMAT

JOINT SOF MASTER PLAN

\section{Basic Plan:}

- Defines USSOCOM missions, functions, and responsibilities

- Describes broad relationships with NCA, JCS, other departments and agencies

- Identifies current doctrine

- States USSOCOM doctrinal and functional goals

- Establishes major milestones

- Responds to national directives

- 1986 SECDEF report to Congress

- President's Report to Congress, October 1987

- SASC report on Washington location, January 1988

\section{2. "Typical" Annex:}

- Baseline: describes what is available in each Service (be it program, policy, aircraft, et al); points out gaps or imbalance.

- Program: describes planned changes in Service SOF policy and programs (should lead toward balanced joint capability to meet requirements).

- USSOCOM Goals: Measures current/programmed Service efforts against joint USSOCOM goals for SOF; identifies differences and identifies means and timetable for resolution. 


\section{Suggested Annexes:}

a. Command Relationships: Describes relationships with assigned forces, components, their parent commands as well as with other U\&S commands, Services, DOD and non-DOD agencies and other groups; identifies planned/necessary adjustments; delineates USSOCOM optimum relationships and goals derived from basic plan.

b. Force Structure: Describes current and future requirements; describes Service baselines and programmed changes; identifies imbalance in timing, quantity, quality of programs; measures program content and phasing against requirements and established USSOCOM force structure goals.

c. Personnel: Discussed in basic paper,

d. Readiness: Describes current status and measurement criteria and planned changes; identifies inadequacies and inconsistencies in readiness status and/or measurement and reporting criteria; establishes USSOCOM goals for improvements in joint force readiness, reporting, and measurement. (Note: Training is an integral factor in readiness; should be examined as a critical factor in either the readiness or personnel annex or considered as separate annex.)

e. Intelligence: Targeting support, dissemination, collection management, and C3I are subjects of associated papers. 
f. Logistics: Describes current status in each Service and programmed change; analyzes potential economies, reduction of duplicative effort, streamlined cross-service initiatives; measures USSOCOM goals for joint readiness; identifies courses of action (component, Service, or DOD) to meet USSOCOM goals.

g. Research, Development, and Acquisition: Subject of associated paper.

h. Communications: Describes current status and programmed change in Service, inter-Service, joint and national-level programs supporting or supported by joint SOF; identifies duplication and/or gaps in connectivity, responsiveness, interoperability (with SOF, non-SOF entities); compares to USSOCOM optimum C3I architecture; identifies courses of action.

i. Mobility: Describes current and planned Service/joint posture; examines selfdeployment, other modes, time phasing of wartime movement, crisis response tailoring, required redundancy, priority of movement and other factors; identifies problem areas and proposed solutions within current/programmed posture; establishes USSOCOM mobility goals and defines required actions necessary to achieve them.

\section{Compartmented Annexes (if required):}

- Share "typical" format (baseline, program, USSOCOM goals).

- Coordination limited to appropriate access within the dimensions of the compartment. 


\section{TITLE: COMMAND RELATIONSHIPS}

2. PURPOSE: To provide USSOCOM an effective plan of action for establishing the command relationships and agreements necessary to provide and employ assigned forces in response to JCSM 71-87 (Missions and Functions).

3. OVERVIEW: Congressional legislation has established ten specific USSOCOM missions. These may be grouped into four major operational functions:

- Combatant special operations, principally unconventional warfare, conducted by the theater unified commands

- Counterterrorist (CT) operations

- Unilateral operations directed by the NCA

- Operations in potential or extant low intensity conflict (LIC) environments

These operational functions require close and cooperative command relationships with:

- Assigned component forces, their parent commands, and the Services

- Service special operations units identified but not assigned (theater SOF, SEALs, MAC Special Operations Low Level forces)

- Unified and Specified Commands

- Selected combined commands

- JCS

- DOD and other government departments, agencies, and groups 
a. Background: The establishment of the U.S. Special Operations Command reflects Congressional concerns over perceptions of past deficiencies in Service and OSD support of special operations forces. Creation of the command was mandated by amendment to Title 10, USC, which was enacted on 18 October 1986. The legislation broadly delineates unique USSOCOM responsibilities and prerogatives. More specific guidance is found in subsequent changes to JCS guidance (JCSP, UCP, Pub 2) and the specific JCS statement of missions and functions approved for the new command (JCSM 71-87). The latter guidance tasks USCINCSOC to establish required formal relationships and agreements with affected commands, Services, DOD and non-DOD agencies, and other groups.

b. Baseline: The inherent thrust of the legislation is to assign USCINCSOC the responsibility, resources, and control necessary to perform his operational functions. A logical corollary implies that USCINCSOC should be assigned only those forces and responsibilities that are dedicated to execution of those functions. Specific language in the law allowing SECDEF to modify the assigned force list, under certain conditions, supports this interpretation. In this context, there are several apparent anomalies involving all three Service components. The following chart reflects required forces not assigned and forces which may be inappropriately assigned. SECDEF decisions concerning organizational alignment are, in some cases, pending. 
Component

ARSO

AFSCO

NAVSOC

JSOC $\underline{\text { Potential Problem Areas }}$

Civil Affairs (CA)

Psychological Operations

Rangers

JFK Special Warfare Center (JFKSWC)

23 AF Dual Hat

Rescue

- WX Reece

- VIP Transport

- MAC Special Operations

Low Level (SOLL)

Forces not assigned

Operational Employment

\section{Comments}

Forces are not dedicated to special operations; bulk of commtment is to conventional force

Same as CA

Dual committed

Not dedicated to SOF; dual hatted to TRADOC

Dual hatted to USSOCOM(SOF forces) and MAC

(rescue, WX, etc.)

Forces not assigned

Forces not assigned

USSOCOM's role

Until all organizational issues are resolved, the baseline composition of USSOCOM forces must be considered to be somewhat tenuous. The USSOCOM staff must identify "work-around" arrangements to accommodate those SOF forces not directly assigned to USSOCOM, e.g., the Navy component forces. Also, dual hatting of component forces dilutes command attention from purely SOF matters. The command must press for early resolution of these baseline issues in order to rapidly develop effective and comprehensive command relationships. 
4. CONCEPT: The diversity of assigned forces and the breadth of USSOCOM responsibilities suggest a natural division of command relationships.

- "Internal" relationships encompass the command's assigned forces (i.e., components, parent commands, and Services). Normally these relationships are clearly defined in command and control terms; however, the current dual-hat nature of some USSOCOM components complicates the issue.

- "External" USSOCOM relationships are those required by assigned responsibilities (EUCOM, PACOM, CIA, DMA, DOS, etc.). These relationships are also contentious since USSOCOM mandated responsibilities are extraordinary and required relationships are complex.

In the first instance, the USSOCOM goal is direct control of assigned forces and establishment of authority to control their quality and readiness. In the latter case, USSOCOM seeks to establish responsive, cooperative relationships which hinge on communications, mutual support, and understanding.

A careful reading of the legislation establishing USSOCOM produces a specific list of units and forces in the JCSP Annex E, which creates a variety of internal issues. Those issues stem from a "patchwork" assignment of missions and forces to USSOCOM Army and Air Force components and from longstanding Navy reluctance to subordinate its forces to another command. A less literal reading of the legislation, coupled with the background leading to its enactment, leads to a "spirit of the law" conclusion that a single senior military commander and supporting headquarters staff are required to provide strong leadership, advocacy, and visibility to the joint special operations mission. The fabric of the law implies that Congress considered the previous leadership to be fragmented, not dedicated. 
This theme is reflected in the establishment of the new ASD/(SO/LIC), the creation of the SOF-only MFP 11, and throughout other directed actions. Viewed objectively, the legislation represents a straightforward effort to establish "who's in charge." Implicit in the effort is a sense that SOF is a full-time mission for USSOCOM and its components. The command's internal relationships should reflect that sense. Clearly, USSOCOM's relationships with assigned forces should reflect direct control and dedication of purpose in order to comply with both the spirit and the letter of the law. The alternative is additional Congressional involvement.

USSOCOM's external relationships are a function of its assigned mission(s), its global responsibilities, and its role as either a supported or a supporting command. Important agreements must be established with DOD elements (e.g., Defense Security Assistance Agency (DSAA), DIA, DMA, SAC) and other government agencies (e.g., CIA, DOS), and cooperative arrangements undertaken with the other unified, specified, and combined commands. In each case, precedents may exist to allow the command to exploit lessons learned.

5. APPROACH: Establishing command relationships is potentially the most open-ended task on the USSOCOM agenda. At the outset, it is essential to establish a plan--a set of actions and alternatives--which satisfies the Congressional mandate, addresses assigned missions and functions, and is consistent with laws, regulations, and policy. Those external relationships and agreements that rely on precedent may be established very quickly; internal relationships unique to the command may take much longer to finalize. 
To be successful, the USSOCOM plan must seek remedies to those deficiencies that led to creation of the command. Further, a review of command relationships during the rescue attempt in Iran, the rescue in Grenada, and other recent operations will expose problems which flawed execution and subsequently led to the passage of legislation to correct these flaws. The "corporate history" of issues and events involving special operations must be clearly understood. Careful historical study will allow recognition and understanding of the events and perspectives which shaped establishment of USSOCOM. This understanding is key to establishing effective command relationships, since it will represent the most likely "going-in positions" for the various players.

A preliminary historical analysis provides USSOCOM a basis upon which to establish subjective milestones to implement the various command arrangements and other agreements required. Developed from collection and examination of recent SOF experience, effective precedent, and useful models, it should yield a sharper definition of Congressional intent and an understanding of the events which shaped that intent. Ultimately, it should produce a comprehensive preliminary listing of formal agreements required. It may also indicate desirable informal agreements which complement and sustain successful relationships in time-sensitive operations.

The second phase of the analysis should identify those similarities in the relationships established by precedent (JSOC, USCENTCOM, USTRANSCOM, possibly others) which adapt readily, in whole or in part, to USSOCOM missions and functions. Much of the precedent for establishment of USSOCOM command relationships has been set by the almost seven-year struggle of the JSOC to develop a similar set of relationships. The JSOC model should provide useful strategies as USSOCOM seeks to 
establish similar, but broader relationships with other commands, Services, and agencies. The functional similarities between USSOCOM and JSOC suggest that there are many existing JSOC command arrangements, memoranda of understanding, and letters of agreement that may be quickly reworked and approved for USSOCOM. For those agreements in which USSOCOM and JSOC are significantly different or divergent, the established JSOC agreements may nonetheless provide useful guides for USSOCOM. Although JSOC's mandate has been evolutionary and confined to a single mission, whereas USSOCOM's is immediate and based on broader legislated mission responsibilities, JSOC remains the purest available model for this effort. An intensive review and comparison of established JSOC internal and external relationships should reveal many that are nearly identical to those required by USSOCOM.

Importantly, the JSOC model should be followed only where it furthers USSOCOM goals. USSOCOM is unique and it should use its unique status to obtain what it must have to do the SOF job. The JSOC precedent, along with its limitations and frustrations, must not constrain USSOCOM.

This phase of the analysis also provides objectives and milestones to achieve essentially non-contentious relationships, although the establishment of requisite USSOCOM, priority and breadth of interest precludes the luxury of "rubber stamp" agreements.

Certainly one of the most important aspects of USSOCOM's external relationships is its interface with the theater SOCs. The experience of the Tactical Air Forces 
(TAF) may in this case provide a better model than the JSOC and represents a longstanding and successful example of the cooperation between a CONUS supplier of forces and theater users.

The third phase of the analysis identifies required relationships which are peculiar to USSOCOM's assigned responsibilities and forces and which do not lend themselves to precedent. By definition, these relationships may involve changes to existing guidance or clarification of legislative intent and may be either formally or informally developed. The analysis should provide recommendations and options for USSOCOM action and should address those issues which appear to be contentious. As an example, the assignment of SOF-related theater search and rescue forces to USSOCOM is an issue which could certainly be difficult to negotiate with the theater CINCs.

6. FEASIBILITY: The nature of USSOCOM's creation denies the command the luxury of an established, historical, command perspective against which goals can be measured and crucial command relationships compared. The background leading to assignment of specific forces and responsibilities to USSOCOM is available and well documented. Collection and analysis of this background is both feasible and necessary to establish the foundation for effective internal and external command relationships.

7. RECOMMENDATIONS: Required eommand relationships are complex and broad. To avoid false starts and wasted effort, USSOCOM needs an objective view of the influences and perspectives which led to the creation of the command. This will provide a basis for successful negotiations and enhance efforts to develop effective command relationships. Recommend the following specific actions: 
a. USSOCOM should compile a historical perspective of factors leading to creation of the command. This objective historical baseline will permit future evaluations of the command's progress, document the strong purposes of the command's origin, and identify all command relationships which have been required in past operations.

- Collect and analyze after-action reports and documents (Holloway Commission, Grenada after-action, others).

- Collect and analyze Congressional and OSD documents (Service POMs, DRB initiatives, testimony).

- Interview Congressional, DOD, and Service staffers and/or principals to gain perspectives on actions taken.

- Compile an objective historical trace of recent events which reflects an institutional starting point for the embryonic USSOCOM.

- Identify all internal and external command relationships required by USSOCOM, as indicated by the historical analysis. Identify any informal relationships which contribute to effective SOF employment.

b. Compare USSOCOM to other commands and organizations to determine formal command relationships which may be adapted readily to USSOCOM needs. The comprehensive comparison will further highlight those required relationships which are unique products of USSOCOM's assigned forces, missions, and responsibilities.

- Compare inherent organizational features of USSOCOM to those of other commands or "models."

- Determine those existing relationships which are readily transferable or easily adaptable to USSOCOM needs.

- Develop a plan with milestones for consummation of those USSOCOM command relationships which may be established by adaptable precedent. 
c. Develop a plan of action for resolution of problems unique to USSOCOM's particular responsibilities. The plan should determine those corrections in specific force and mission assignments (letter of the law) which are required to best fulfill USSOCOM's broader responsibilities (sense of the law).

- Identify those command relationships dictated by the law or by other guidance which may require modification in order to fulfill USSOCOM's broad responsibilities.

- Analyze these relationship's modifications to determine if they may be amended or modified within the flexibility of the legislation.

- Develop recommendations to JCS for required changes within existing law.

- Develop recommendations for JCS and SECDEF to request factof-life changes to the existing law, if required. 